\title{
Sex Differences in Opioid-Mediated Effects: Role of Androgens
}

\author{
Jessica Sharp ${ }^{1}$, Tallia Pearson ${ }^{1}$, and Mark Smith ${ }^{1}$ \\ ${ }^{1}$ Davidson College
}

October 2, 2020

\begin{abstract}
An abundance of data indicate there are sex differences in endogenous opioid peptides and opioid receptors, leading to functional differences in sensitivity to opioid-mediated behaviors between males and females. Many of these sex differences are mediated by the effects of gonadal hormones on the endogenous opioid system. Whereas much research has examined the role of ovarian hormones on opioid-mediated endpoints, comparatively less research has examined the role of androgens. This review describes what is currently known regarding the influence of androgens on opioid-mediated endpoints and how androgens may contribute to sex differences in opioid-mediated effects. The review also addresses the clinical implications of androgenic modulation of opioid-mediated behaviors and suggests future lines of research for preclinical and clinical investigators, We conclude that further investigation into androgenic modulation of opioid-mediated effects may lead to new options for addressing conditions such as chronic pain and substance use disorders.
\end{abstract}

\section{Introduction}

A large body of literature reveals significant sex and gender differences in opioid-mediated effects. Many of these differences are clinically meaningful and have public health implications. For instance, sex differences in sensitivity to opioid-mediated analgesia contribute to significant differences in the potency and efficacy of opioid analgesics between men and women treated for acute and chronic pain (Craft, 2008; Neisters et al., 2010; Loyd \& Murphy, 2014; Lee \& Ho, 2013). Similarly, sex differences in opioid-mediated reward contributes to differences in the risk of developing an opioid use disorder in men and women prescribed opioids or using opioids recreationally (Lopresti et al, 2020; Kokane \& Perotti, 2020; Becker \& Chartoff, 2019). These sex differences are apparent at preclinical, clinical, and epidemiological levels of analysis, and a number of mechanisms that may contribute to these differences have been explored.

One area that has received significant research attention concerns the role of gonadal hormones in opioidmediated effects. Gonadal hormones are an obvious target for investigation given their known role in determining the potency and efficacy of drugs from many pharmacological classes. In regard to opioids, much of the prior research has focused on the role of ovarian hormones, particularly estrogen and progesterone, in the modulation of opioid-mediated effects, and a number of review articles have described their effects on opioid-related outcomes (Becker and Koob, 2016; Fillingim, 2009; Kokane \& Perotti, 2020; Huhn, Berry, \& Dunn, 2018). A smaller body of literature has described the role of androgens in opioid-mediated effects, and we are not aware of any comprehensive attempts to synthesize this literature. The goal of this review is to describe the research examining the effects of androgens on opioid-mediated effects, and how androgens may contribute to clinically relevant sex differences, especially in areas of opioid analgesia and reward.

\section{Sex Differences in Opioid-Related Effects}

\subsection{Addiction-Related Outcomes}

\subsubsection{Human Studies}


Opioids were involved in approximately $70 \%$ of all drug-related overdoses in the United States in 2018 (Wilson et al., 2020). Although men are more likely to experience an opioid overdose, the risk of overdose has increased more rapidly in women than men since 2000 (Lopresti et al., 2020). There are also notable sex differences in the use of licit vs. illicit opioids. For instance, men are more likely to use heroin, use heroin in larger quantities, and use heroin for a longer period of time than women (Back et al., 2010; Back et al., 2011; Kuhn, 2016; NIDA, 2020). In contrast, women are more likely to use prescription opioids (Back et al., 2011; Green et al., 2009), are more likely to have their first opioid experience with prescription opioids (Bawor et al., 2015a; see reviews by Lee \& Ho, 2013; Kokane \& Perotti, 2020), are more likely to be prescribed opioids, and are more likely to have opioid prescriptions filled than men (Schieber et al., 2020). These findings may be related to the observation that women report more general bodily pain and are more likely to suffer from pain disorders than men (Fillingim et al., 2009; Cepeda \& Carr, 2003; Darnell et al., 2012; NIDA, 2020). Women are also more likely to meet diagnostic criteria for opioid abuse and have a substance use disorder attributed to prescription opioids than men (NIDA, 2020; Green et al., 2009; Serdarevic et al., 2017; see review by Kokane \& Perotti, 2020).

Women are also more likely to experience negative consequences related to opioid use compared to men. For example, women meet the diagnostic criteria for addiction quicker (Anglin, Hser, \& McGlothin, 1987; Hser, Anglin, \& Booth, 1897), escalate to higher doses faster (for review, see Back et al., 2011; Becker \& Chartoff, 2019; Kokane \& Perotti, 2020; Lopresti, et al., 2020; but see Kaplovich et al., 2015), report more physical and socioeconomic negative side effects (Cepeda et al., 2003; Back et al., 2011; McHugh et al., 2013; Bawor et al., 2015a; Huhn et al., 2019), report more withdrawal symptoms (Kokane \& Perotti, 2020; Giacomuzzi et al., 2005, Dunn et al., 2018), experience more craving (Yu et al., 2007; Back et al., 2011; Lee \& Ho, 2013), and are less likely to seek treatment over their lifetime (for review, see Greenfield et al., 2007; Kokane \& Perotti, 2020) than men. These negative consequences are associated with greater levels of stress, and women experience more opioid craving during stressful situations then men (Moran et al., 2018).

Remarkably, there have been very few studies examining the possible influence of gonadal hormones on sex differences in opioid use/abuse in human populations, and we could not find any experimental studies that systematically addressed the potential role of androgens in abuse-related effects in humans. There are a few reports describing testosterone-induced increases in positive affect in opioid users (Blick et al., 2012; Roantree \& Zylicz, 2009), but these studies have small sample sizes and lack relevant control conditions. Consequently, the role of androgens in opioid intake is mostly unknown at this time.

\subsubsection{Animal Studies}

Most studies indicate that male rats are less sensitive to the rewarding and reinforcing effects of heroin and other opioids than female rats (see reviews by Becker \& Koob, 2016; Craft, 2008; Kokane \& Perotti, 2020; Becker \& Chartoff, 2019). For instance, male rats exhibit lower levels of opioid intake and take longer to acquire oral and IV opioid self-administration compared to females (Carroll et al., 2002; Cicero et al., 2003; Lacy et al., 2016; Alexander et al., 1978; Lynch \& Carroll, 1999), but this effect can vary by factors such as dose, schedule of reinforcement, and level of food restriction (Mavrikaki et al., 2017). Male rats also demonstrate a morphine-induced conditioned place preference over a narrower range of doses than females (Cicero et al., 2000; Karami \& Zarrindast, 2008), suggesting that male rats are less sensitive to both the reinforcing and conditioned rewarding effects of opioids.

There is some evidence that male rats may be less sensitive to the discriminative stimulus effects of mu opioids. For example, male rats acquire a morphine vs. saline discrimination at a slower rate than females, and mu opioid agonists are less potent in males than females in substitution tests (Craft et al., 1996). Male rats are more sensitive to the rate-suppressing effects of opioids than females, which can complicate interpretation of drug discrimination data due to biases in reinforcement frequency between drug and vehicle sessions between the two sexes. Indeed, when schedule parameters are changed to eliminate reinforcement bias, sex differences in the discriminative stimulus effects of opioids are no longer apparent (Craft et al., 1998a). In contrast to that seen with mu opioids, male rats are more sensitive to the discriminative stimulus effects of kappa opioids. For instance, male rats acquire a U69,593 vs. saline discrimination faster than 
females, and kappa agonists are more potent in males than females in substitution tests. Furthermore, unlike that seen with mu agonists, sex differences are not observed to the rate-suppressing effects of kappa agonists (Craft et al., 1998b).

Opioid-induced tolerance and physical dependence are two additional areas in which consistent sex differences are observed. Male rats develop tolerance at a faster rate (Holtman \& Wala, 2005; Kasson \& George, 1984; South et al., 2001) and to a greater extent (Craft et al., 1999; Barrett et al., 2001; Mousavi et al., 2007; but see Holtman et al., 2004) than females. These sex differences are mediated, in part, by gonadal hormones. For instance, gonadectomy of both males and females abolishes sex differences in the extent to which tolerance develops (Mousavi et al., 2007), and castration reduces the rate of tolerance development in males relative to both intact males and testosterone-treated females (South et al., 2001).

Sex differences in opioid-induced tolerance may be due, in part, to sex differences in sensitivity to the acute effects of opioids. Males are more sensitive to the acute antinociceptive effects of opioids, meaning that a given dose is functionally greater in males than females on a $\mathrm{mg} / \mathrm{kg}$ basis (see Section 2.2.2). If males are more sensitive to a given dose of an opioid, and if that dose is functionally greater in males than in females, then tolerance will be greater at that dose in males than females (Dahan et al., 2008). Supporting this notion, male and female rats demonstrate comparable degrees of opioid-induced tolerance when functionally equivalent doses of a drug are administered chronically (Barrett et al., 2001).

Similar sex differences have been reported for opioid-induced physical dependence and withdrawal (see reviews by Craft, 2008; Becker \& Koob, 2016; Bodnar \& Kest, 2010). Male rodents undergoing spontaneous withdrawal from morphine exhibit greater weight loss, higher withdrawal scores, and earlier withdrawal symptoms compared to females, although the duration of withdrawal symptoms vary across species (Cicero et al., 2002a; Papelo \& Contarino, 2006). Male rodents also display more severe naloxone-precipitated withdrawal symptoms than females, including greater weight loss, jumping, and wet-dog shakes (Craft et al., 1999; Diaz et al., 2001, 2005; Nayebi \& Rezazadeh, 2008; Sagedhi et al., 2009; but see Cicero et al., 2002a). As noted above in regard to sex differences in opioid-induced tolerance, sex differences in opioid-induced physical dependence must take into consideration sex differences in acute opioid sensitivity, especially if the dose chosen for chronic administration is not functionally equivalent between males and females (Craft et al., 2008).

\subsection{Pain and Opioid-Induced Analgesia/Antinociception}

\subsubsection{Human Studies}

A number of excellent reviews have been published on sex differences in opioid analgesia/antinociception (Craft, 2008; Dahan et al., 2008; Fillingim et al., 2009; Bodnar \& Kest, 2010; Niesters et al., 2010; Rasakham \& Liu-Chen, 2011; Lee \& Ho, 2013; Loyd \& Murphy, 2014; Nasser \& Afify, 2019; Mogil, 2020), and several reviews have specifically addressed sex differences in pain sensitivity and sensitivity to opioid analgesia in humans (Craft, 2008; Fillingim et al., 2009; Lee \& Ho, 2013; Loyd \& Murphy, 2014; Mogil, 2020; Niesters et al., 2010;). Clinically, women report more pain and require significantly more morphine to alleviate pain than men (Aubrun et al., 2005; Cepeda \& Carr, 2003; but see Chia et al., 2002). Similarly, women have lower pain thresholds and pain tolerances than men on laboratory pain measures (Al'Absi et al., 2004; Fillingim et al., 2004; Fillingim et al., 2005; Zacny \& Beckham, 2004). Laboratory studies measuring sex differences in opioid-induced analgesia are more equivocal, but generally report that men are more sensitive to opioid analgesia on some (but not all) pain measures (Fillingim et al., 2004; Zacny \& Beckham, 2004).

\subsubsection{Animal Studies}

Similar to that observed with humans, female animals exhibit greater baseline nociceptive sensitivity in preclinical models of pain (Mogil, 2020). In these models, opioid agonists produce greater antinociceptive effects in males than females, evidenced by greater potency and/or efficacy in males across a therapeutic dose range (See Craft, 2008; Bodnar \& Kest, 2010). These differences are more apparent when opioids are administered via supraspinal than spinal or peripheral routes (see Craft, 2008; Dahan et al., 2008; Bodnar \& 
Kest, 2010), suggesting that sex differences are mediated primarily by differences in the pharmacodynamics (rather than pharmacokinetics) of these drugs between males and females.

The magnitude of these sex differences differs across strain of subject, ranging from minimal to large differences in potency and/or efficacy between males and females (Barrett et al., 2002; Kasson \& George,1984; Kest et al., 1999; Cook et al., 2000; Terner et al., 2003; 2006). The magnitude of these sex differences also vary across opioids based on their relative selectivity for - and their relative intrinsic efficacy at - the three primary opioid receptors (i.e., mu, kappa, delta; for review, see Bodnar \& Kest, 2010; Dahan et al., 2008). Moreover, age differences in opioid-induced antinociception can interact with sex differences to amplify (or minimize) differences between males and females across age groups (White et al., 2008). Finally, differences between males and females can vary across nociceptive stimuli (e.g., mechanical vs. thermal), but these typically involve quantitative rather than qualitative differences across experimental endpoints, with males being more sensitive than females under the majority of experimental conditions (e.g., mechanical: Bai et al., 2015; Cicero et al., 1996; thermal: Cicero et al., 1996; Craft et al., 1999; Cook et al., 2000; Barrett et al., 2001; Craft \& Bernal, 2001; Terner et al., 2002; Holtman et al., 2004; Holtman \& Wala, 2004; Stoffel et al., 2005; Cataldo et al., 2005; Peckham et al., 2011). Although some examples of greater sensitivity in females have been reported (e.g., Stoffel et al., 2005; Tershner et al., 2000), there is no obvious commonality among these studies to predict conditions in which women would be more sensitive to opioid-induced analgesia than men in therapeutic settings.

Sex differences can be eliminated by a number of manipulations, but those manipulations generally involve rendering opioids less effective in both sexes. For instance, chronic morphine administration leads to antinociceptive tolerance in both sexes and abolishes the sex difference observed in naïve subjects (Holtman et al., 2004). Similarly, mutant mice that lack $\mathrm{GIRK}_{2}$ are less sensitive to opioid-induced antinociception than wildtype mice, and do not exhibit the sex differences that are apparent in wildtype mice (Mitrovic et al., 2002). Alternatively, sex differences in opioid-induced antinociception can be manipulated via hormonal manipulation, particularly via perturbation of endogenous androgens (e.g., Elliott et al., 2003; Terner et al., 2002, and see Section 3.2.2).

\subsection{Unconditioned Effects of Opioids}

Sex differences in opioid sensitivity often extend to unconditioned drug effects. For example, male rats are more sensitive than female rats to morphine-induced expression of the immediate-early gene $c$-Fos and to morphine-induced Straub tail (D'Souza et al., 2002). Similarly, male rats are more sensitive to the locomotorsuppressive effects of morphine than female rats (Craft et al., 2006; Holtman et al., 2004; Stewart \& Rodaros, 1999), and male mice are more sensitive to the locomotor-stimulating effects of morphine than female mice (Kavaliers \& Innes, 1986). Moreover, male rodents are more sensitive to the antidiuretic (Craft et al., 2000) and respiratory depressant effects (Craft et al., 1999) of morphine than female rodents, although this latter effect may vary across species (see Dahan et al., 2008; Sarton et al., 1999). In contrast, male rodents are less sensitive than female rodents to the immunological/inflammatory effects of morphine (Elliott et al., 2003; 2006) and to the thermoregulatory (both hypothermic and hyperthermic) effects of morphine (Kest et al., 2000; Quock et al., 1985; but see Kasson \& George, 1984).

\subsection{Opioid Receptors and Opioid Peptides}

The endogenous opioid peptides, beta-endorphin, met/leu-enkephalin and dynorphin preferentially bind to mu, delta and kappa opioid receptors, respectively (Nyberg \& Hallberg, 2012; Reisine, 1995), and there is ample evidence that the concentrations of these peptides and receptors differ between males and females (see Huhn et al., 2018; Rasakham \& Liu-Chen, 2011; Chartoff \& Mavrikaki, 2015). Evaluating these sex differences is often difficult because the magnitude systematically waxes and wanes as a function of circulating ovarian hormones in females (e.g., Flores et al., 2003). Evaluation of these sex differences is also complicated by inconsistences across neuroanatomical regions and developmental stages, suggesting multiple regulatory roles of the endogenous opioid system that vary both within and across sexes.

\subsubsection{Endogenous Opioid Peptides}


Prepubescent rat pups do not exhibit significant sex differences in concentrations of beta-endorphin in the medulla, midbrain, diencephalon, telencephalon, hippocampus, striatum, cortex, and amygdala (Bayon et al., 1979). A lack of sex differences in beta-endorphin levels continues into adulthood in several key areas, including the median eminence, brainstem, parietal lobe, and the neurointermediate lobe of the pituitary (Petraglia et al., 1982; Pluchino et al., 2009). Sex differences emerge in some areas, with adult males exhibiting greater beta-endorphin concentrations in the prefrontal cortex than females, and with adult females exhibiting greater beta-endorphin concentrations in the hypothalamus, hippocampus and anterior pituitary than males (Pluchino et al., 2009; Wardlaw, 1986).

Similar to that reported for beta-endorphin, prepubescent rat pups do not exhibit sex differences in met/leuenkephalin concentrations across many regions, including the medulla, midbrain, diencephalon, telencephalon, hippocampus, striatum, and amygdala (Bayon et al., 1979). Some significant sex differences emerge in adulthood, and these differences are region specific. For instance, adult females have greater concentrations of met-enkephalin immunoreactive fibers within the preoptic area (Watson et al, 1986) and greater concentrations of met- and leu-enkephalin in the cerebral cortex (Tang \& Man, 1991) and leu-enkephalin in the CA3 region of the hippocampus (Van Kempen et al., 2013) than males. In contrast, adult males have significantly greater concentrations of met- and leu-enkephalin in the pituitary, including the anterior pituitary, than females (Hong, Yoshikawa, \& Lamartinere, 1982; Yoshikawa \& Hong, 1983; Tang \& Man, 1991). These sex differences are due, in part, to gonadal hormones, given that both castration in males and ovariectomy in females reduces the magnitude of these differences (Yoshikawa \& Hong, 1983). Finally, males have significantly more neurons containing proenkephalin mRNA within the anteroventral periventricular nucleus of the hypothalamus compared to females (Simerly, 1991).

A limited amount of data suggests sex differences in dynorphin concentrations across a few critical brain regions. For instance, males have higher concentrations of dynorphin in the anterior pituitary compared to females (Molineaux et al., 1986), whereas females have significantly more neurons containing prodynorphin mRNA in the anteroventral periventricular nucleus of the hypothalamus (Simerly, 1991), and greater dynorphin concentrations in the CA3 region of the hippocampus (Van Kempen et al., 2013) compared to males. There is also evidence that these sex differences are due in large part by the activity of gonadal hormones. For instance, females rats in diestrus and proestrus have significantly higher preprodynorphin mRNA levels within the spinal cord following injection of CFA relative to both male rats and female rats in estrus (Bradshaw et al, 2000). Moreover, ovariectomy increases preprodynorphin levels in the spinal cord relative to both intact and gonadectomized males, and castration significantly decreases preprodynorphin levels in the spinal cord of males (Bradshaw et al., 2000).

\subsubsection{Opioid Receptors}

Sex differences are also apparent for all three major opioid receptor subtypes. Male rats have significantly higher mu receptor protein levels in the spinal cord and midbrain (Kren et al., 2008; Bernal et al., 2007), and sex differences in sensitivity to the antinociceptive effects of mu opioids $(\mathrm{M}>\mathrm{F})$ can be traced to functional differences in the density of mu receptors in the periaqueductal grey area ( $\mathrm{M}>\mathrm{F}$; Loyd et al., 2008). Data examining sex differences in other areas are less clear, with conflicting findings in the hypothalamus that vary across age (Rimanóczy \& Vathy, 1995; Limonta et al., 1991; Maggi et al., 1991). Complicating matters further, sex differences in mu receptor concentrations can either be exaggerated or minimized by the sex and position of intrauterine siblings, with nearby male and female fetuses producing masculinizing and feminizing effects, respectively; however, this effect too varies across brain region (Morely-Fletcher et al., 2003).

Male rats have significantly greater concentrations of delta opioid receptors within the dentate gyrus than female rats (Williams et al., 2011). Male rats also have greater delta receptor concentrations within the CA1 region of the hippocampus, but this is dependent on the phase of the estrous cycle in females (Williams et al., 2011). Similarly, male rats have greater delta receptor concentrations in the amygdala, but this effect also depends on the estrous phase of females (Wilson, Mascagni, \& McDonald, 2002). In both of these cases, sex differences are confined to the proestrus phase of the estrous cycle. Females exhibit greater concentrations of delta receptors in CA3 pyramidal cells of the hippocampus, but this effect is also dependent on the estrous 
cycle and only apparent during proestrus. Complicating matters further, acute and chronic stress alter delta receptors in a sexually dimorphic fashion, which has implications for sex differences in learning and memory in response to different types of stressors (Mazid et al., 2016).

Although limited, the available data suggest that female rats have significantly higher concentrations of kappa receptors in the spinal cord and hindbrain (but not necessarily midbrain) compared to males (Kren, Haller, \& Welch, 2008; Drake et al., 2007). These differences are highly dependent on the estrous cycle, with kappa receptor density in females increasing within the spinal cord during proestrus and increasing in both the spinal cord and medulla during estrus (Drake et al., 2007; Harris et al., 2004). Less is known regarding sex differences in kappa receptors within the forebrain.

The studies described in this section reveal that differences in opioid peptides and opioid receptors vary across neuroanatomical region and vary across age and developmental stage. Importantly, concentrations of these various peptides and proteins are under dynamic regulation by gonadal hormones in both sexes. In females, concentrations of endogenous peptides and receptors fluctuate significantly over the course of the estrous cycle, creating and then eliminating sex differences in a cyclic fashion. Given evidence that these variations in peptide and receptor concentrations have functional consequences (e.g., Bradshaw et al., 2000; Flores et al., 2003; Loyd, Wang, \& Murphy, 2008; Williams et al., 2011; Drake et al., 2007; Harris, Chang, \& Drake, 2004), determinations of sex differences in opioid sensitivity should take into account the phase of the estrous cycle when those data are available.

\section{Androgenic Control of Opioid-Related Effects}

\subsection{Abuse-Related Outcomes}

\subsubsection{Humans}

Males are significantly more likely to use and abuse androgenic anabolic steroids (AAS) compared to females (Kanayama et al., 2010; Kanayama et al., 2018; Wood, 2008). In humans, AAS abuse is often a precursor to the abuse of other drugs, particularly opioids (Kanayama et al., 2003; Skarberg et al., 2009; Kanayama et al., 2009a; Kanayama et al., 2009b). Indeed, several studies have reported a relationship between admission for opioid treatment and a prior history of AAS use (Trenton \& Currier, 2005; Kanayama et al., 2009a; Ranjan et al., 2014), leading investigators to conclude that AAS abuse increases the risk of opioid addiction (Kanayama et al., 2018; Kanayama et al., 2003). Opioid use also occurs prior to and concurrently with AAS abuse, suggesting that opioid use also increases susceptibility to AAS abuse (Gårevik \& Rane, 2010; Wines et al., 1999; Ranjan et al., 2014; Skarberg et al., 2009; McBride et al., 1996; Kindlundh et al., 1999). Collectively, such findings suggest that opioid agonists and AAS may mutually enhance the abuse liability of one another, and this may be particularly true in men.

\subsubsection{Animals}

Testosterone produces positive reinforcing and conditioned rewarding effects in preclinical models. Intact male hamsters reliably self-administer greater amounts of oral testosterone than vehicle in a two-bottle choice test (Johnson \& Wood, 2001). Similarly, nose poking can be reliably maintained by intravenous infusions of testosterone in intact male rats (Wood et al., 2004) and intraventricular infusions of testosterone in intact male and female hamsters (Peters \& Wood, 2004). Testosterone replacement increases intraventricular intake of exogenous testosterone in castrated male hamsters (DiMeo \& Wood, 2004), suggesting that circulating androgens increase sensitivity to testosterone self-administration. Male hamsters will also self-administer the androgenic metabolite of testosterone, dihydrotestosterone (DHT), and low (but not high) doses of its antiandrogenic metabolite, estradiol (DiMeo \& Wood, 2006). Testosterone produces a conditioned place preference in intact male rodents following either systemic injections (Alexander et al., 1994; Arnedo et al., 2000, 2002; but see Caladrone et al., 1996) or site-specific injections into the nucleus accumbens shell (Frye et al., 2002; Packard et al., 1997) or medial preoptic area (King et al., 1999). Importantly, the positive reinforcing effects of testosterone are mediated by endogenous opioid activity, given that pretreatment with the opioid antagonist naltrexone blocks the reinforcing effects of testosterone in intact male hamsters (Peters 
\& Wood, 2004).

The effects of androgens on the positive reinforcing and conditioned rewarding effects of opioids vary across species and schedule of reinforcement. Pretreatment with the androgen receptor agonist, nandrolone, enhances morphine-induced place preference in intact male rats (Chow et al., 2016) but reduces morphine-induced place preference in intact male mice (Célérier et al., 2003). Moreover, chronic treatment with nandrolone significantly decreases morphine intake in intact male rats responding on an FR1 schedule of reinforcement but does not alter morphine intake on a PR schedule (Cooper \& Wood, 2014).

Testosterone does not reliably serve as a discriminative stimulus in traditional animal models (Wood et al., 2011; but see De Beun et al., 1992), but androgens modulate the discriminative stimulus effects of mu opioids in male rats. For instance, endogenous androgens enhance the discriminative stimulus effects of mu opioid agonists, as evidenced by reductions in the potency and efficacy of mu agonists to substitute for morphine in a drug discrimination assay following castration (Craft et al., 1999). Paradoxically, endogenous androgens attenuate the rate-decreasing effects of mu opioids in drug discrimination tests, as evidenced by increases in sensitivity to the rate-suppressing effects of mu opioids following castration (Craft et al., 1999).

Androgens decrease the development of tolerance to opioids. For instance, chronic treatment with nandrolone attenuates the development of tolerance to the antinociceptive effects of morphine in intact male mice (Célérier et al., 2003) and in gonadectomized male and female rats (Philipova et al., 2003). Similarly, chronic (but not acute) treatment with finasteride, a $5 \alpha$-reductase enzyme inhibitor that prevents the reduction of testosterone to DHT, attenuates the development of tolerance to the antinociceptive effects of morphine in intact male rats (Verdi \& Ahmadiani, 2007).

Chronic treatment with androgens generally increases the severity of naloxone-precipitated withdrawal in morphine-treated male and female rodents (Célérier et al., 2003; Nayebi \& Rezazadeh, 2008; Sadeghi et al., 2009; Philipova et al., 2003), suggesting that androgens increase the severity of opioid-induced physical dependence. Lending further support for this premise, treatment with the androgen receptor antagonist, flutamide, attenuates naloxone-precipitated withdrawal in morphine-treated male rats (Nayebi \& Rezazadeh, 2008). Similarly, castration attenuates naloxone-precipitated withdrawal in morphine-treated male rodents, and this effect is blocked by supplemental treatment with testosterone (Nayebi \& Rezazadeh, 2008; Sadeghi et al., 2009). In contrast, both acute and chronic treatment with finasteride decreases naloxone-precipitated opioid withdrawal in morphine-treated male rats (Verdi \& Ahmadiani, 2007).

Androgens do not produce an opioid-mediated withdrawal syndrome in the absence of concurrent mu agonist administration. For instance, opioid antagonists do not precipitate withdrawal in intact male mice treated with nandrolone (Célérier et al., 2003), intact male monkeys treated with testosterone (Negus et al., 2001), or intact male hamsters self-administering testosterone (Peters \& Wood, 2004). However, many of the symptoms of AAS withdrawal are qualitatively similar to those of opioid withdrawal, suggesting some overlapping mechanisms may be at play (see Brower et al., 1989; Kashkin \& Kleber, 1989; Trenton \& Currier, 2005)

\subsection{Antinociception and Androgenic Activity}

\subsubsection{Human Studies}

Circulating levels of free testosterone are positively associated with greater pain thresholds (i.e., decreases in pain sensitivity) in normal men (Apkhazava et al., 2018) and men with hypogonadism receiving testosterone therapy (Glintborg et al., 2020). Circulating levels of estradiol are inversely associated with greater pain thresholds in women (Bartley et al., 2015); however, circulating levels of testosterone are positively associated with greater pain thresholds in women, just as they are in men (Bartley et al., 2015; Teepker et al., 2010). Studies examining men with hypogonadism report that testosterone replacement therapy increases pain thresholds and decreases pain sensitivity relative to either placebo controls or their own baselines (Raheem et al., 2017; Basaria et al., 2015; Aloisi et al., 2011; Daniell et al., 2006; AminiLari et al., 2019; Roantree \& Zylicz, 2009, but see Glintborg et al., 2020). Finally, transgender individuals transitioning from female to male typically demonstrate a decrease in pain sensitivity upon treatment with testosterone (Aloisi et al., 
2007).

Coinciding with reductions in pain sensitivity, testosterone treatment generally decreases the need for opioid analgesia, allowing for reductions in dose or frequency of use. For instance, men with hypogonadism typically reduce their intake of opioid analgesics upon the initiation of testosterone replacement therapy relative to their own baseline and to a control population (Raheem et al., 2017; Roantree \& Zylicz, 2009). There are several exceptions to these findings (e.g., Basaria et al., 2015; Aloisi et al., 2011; Daniell et al., 2006), but much of that literature is limited by small sample sizes and heterogenous populations.

\subsubsection{Animal Studies}

Preclinical studies yield ample evidence that testosterone and androgenic activity are involved in nociceptive processes. Male rats castrated as adults have lower nociceptive thresholds in response to thermal and electrical stimuli than castrated rats given testosterone replacement (Borzan \& Fuchs, 2006; Pednekar \& Mulgaonker, 1994). Moreover, castrated male rats have lower nociceptive thresholds in response to mechanical stimuli following carrageenan-induced inflammation relative to castrated rats treated with testosterone (Borzan \& Fuchs, 2006). Testosterone also reduces formalin-induced licking in females, suggesting that the effects of androgens on nociceptive processes are not sex dependent (Aloisi et al., 2004). There is also evidence that androgen-induced increases in nociceptive thresholds are centrally mediated, given that intrahippocampal administration of testosterone, DHT, or $3 \alpha$-androstanediol (a DHT metabolite) increases nociceptive thresholds in response to thermal stimuli in castrated male rats (Edinger \& Frye, 2004, 2005). Finally, swimming increases nociceptive thresholds in castrated rats, and this effect is enhanced by testosterone administration. Importantly, naloxone blocks this effect, suggesting that the effects of testosterone on nociceptive thresholds is mediated by endogenous opioids (Sharma et al., 2019).

The effects of androgens on opioid-induced antinociception are somewhat equivocal (see reviews by Craft et al., 2004; Dahan et al. 2008; and Nasser \& Afify; 2020), but an abundance of data suggest that androgens increase opioid-mediated antinociception under many conditions. For instance, neonatal castration decreases the antinociceptive effects of morphine in adult male rats in both thermal and inflammation-related nociceptive assays (Borzan \& Fuchs, 2006; Krzanowska et al., 2002). In addition, testosterone treatment in neonatal females increases the antinociceptive effects of morphine in adulthood (Cicero et al., 2002b, Krzanowska et al., 2002), thereby reducing the magnitude of sex differences in opioid antinociception described previously (See Section 2.2.2). Similar effects have been reported in adult rats. For instance, castration decreases sensitivity to a wide range of mu and kappa agonists in adult rats, and these effects are observed across different strains and behavioral assays (Bai et al., 2015; Terner et al., 2002; Stoffel et al., 2005). Moreover, testosterone increases the antinociceptive effects of both mu and kappa agonists in adult male rats following castration (Stoffel et al., 2003, 2005; Sumner et al., 2006). Finally, finasteride increases testosterone concentrations and enhances the antinociceptive effects of morphine (Verdi \& Ahmadiani, 2007).

Complicating a clear understanding of the role of androgens in opioid-mediated antinociception are several studies reporting no effect of androgen manipulation on opioid sensitivity. For instance, multiple studies in male rats report that the antinociceptive effects of morphine are not altered by castration (Cicero et al., 1996; Cicero et al., 2002b; Islam et al., 1993; Kepler et al., 1989; Krzanowska \& Bodnar, 1999) or by testosterone replacement (Peckham et al., 2011). Similarly, neither acute nor chronic exposure to the androgen receptor agonist, nandrolone, influences the antinociceptive effects of morphine in male mice (Célérier et al., 2003), and chronic testosterone treatment does not alter the antinociceptive effects of morphine in male monkeys (Negus et al., 2001) or a kappa agonist in sheep (Cook et al., 1998). Testosterone treatment also does not alter the antinociceptive effects mu, kappa, or mixed-action opioids in female monkeys following ovariectomy (Negus \& Mello, 2002). The picture is also complicated by isolated reports of androgen-induced decreases in opioid-mediated antinociception. For example, nandrolone and DHT reduce the antinociceptive effects of morphine in intact male rats (Philipova et al., 2003; Tsutsui et al., 2016), and testosterone reduces the antinociceptive effects of a delta agonist in gonadectomized male rats (Stoffel et al., 2005). Findings such as these indicate that androgens can interact with factors such as species, opioid receptor subtype, and behavioral assay to influence opioid-mediated antinociceptive processes. 
Despite these seemingly contradictory findings, there is a strong correspondence within studies linking sex differences in opioid-induced antinociception to androgenic modulation of opioid-induced antinociception. For instance, sex differences between males and females are partially or completely eliminated by neonatal (Cicero et al., 2002b; Krzanoskwa et al., 2002) or adult (Bai et al., 2015; Stoffel et al., 2003, 2005; Terner et al., 2002) castration of males, or by masculinization of females via neonatal testosterone administration (Cataldo et al., 2005; Cicero et al., 2002b; Krzanoskwa et al., 2002). Indeed, studies failing to identify androgenic mechanisms of sex differences in opioid sensitivity are much less common and often fail to identify an alternative mechanism (e.g., Cicero et al., 1996; Kepler et al., 1986; Peckham et al., 2011).

\subsection{Effects of Androgens on Unconditioned Effects of Opioids}

Opioid use decreases androgenic activity in males, leading to clinically relevant hypogonadism in long-term users of medicinal and recreational mu agonists (see reviews by AminiLari et al., 2019; Bawor et al., 2015b; O'Rourke \& Wosnitzer, 2016; Yilmaz et al., 1999; Ho, 2019). In contrast, comparatively less research has been conducted on both endogenous and exogenous androgens influence unconditioned opioid-mediated effects. The few available studies report little consistency across the disparate endpoints examined.

Chronic self-administration of intracerebroventricular testosterone produces significant mortality resulting from severe autonomic depression in as little as two weeks (Peters \& Woods, 2004), and lethality from AAS overdoses resembles that of morphine and heroin (Peters \& Woods, 2004; Wood, 2006). Repeated exposure to testosterone decreases respiration, body temperature, and locomotor activity in male hamsters, and these effects can be blocked by the opioid receptor antagonist, naltrexone (Peters \& Woods, 2004). Moreover, both acute and chronic administration of nandrolone increases morphine-induced hypothermia in intact male mice (Célérier et al., 2003). In contrast, exogenous androgens do not alter morphine-induced locomotor activity in intact male rats and mice (Célérier et al., 2003; Cooper \& Wood, 2014), and castration (with or without testosterone replacement) does not alter morphine-induced locomotor activity (Craft et al., 2006).

G protein-coupled inwardly rectifying potassium channels (GIRKs) are the primary post-synaptic effector of $\mathrm{mu}$ opioids and are at least partly responsible for sex differences in opioid-induced antinociception. Endogenous androgens increase GIRK $_{2}$ gene expression in the brain and spinal cord in male rats as evidenced by decreases in GIRK $_{2}$ expression following castration; however, these effects cannot be reversed by exogenous testosterone treatment (Ahanagar et al., 2008). In intact male rats, mu opioid agonists acutely increase $c$-fos and JunB gene expression in multiple brain regions (e.g., D'Souza et al, 2001; Harlan et al., 2000). Chronic treatment with exogenous androgens significantly decreases morphine-induced $c$-fos and JunB gene expression in the caudate putamen (Harlan et al., 2000), suggesting that androgens can functionally antagonize the effects of mu opioids under some conditions. Some of the effects of androgens on opioid-mediated responses can be attributed to activational rather than developmental effects, given that a single bolus dose of testosterone on postnatal day 1 does not alter the expression of mu opioid receptors, morphine-induced dopamine release, morphine-induced locomotor effects, or morphine-induced conditioned place preference in adulthood in either male or female rats (Velásquez et al., 2019).

\subsection{Opioid Peptides and Receptors}

\subsubsection{Opioid Peptides}

Both castration and administration of exogenous androgens influence the concentrations of opioid peptides and opioid receptors (for review, see Nyberg \& Hallberg, 2012; Mhillaj et al., 2015; Wood, 2008). These effects often vary across neuroanatomical loci, but some general patterns are evident from the existing literature.

\subsubsection{Beta-endorphin}

The qualitative effects of androgens on beta-endorphin concentrations depend on the region examined. In many regions, particularly in plasma and pituitary, androgenic activity consistently increases beta-endorphin concentrations. For instance, castration decreases beta-endorphin in plasma, whole pituitary, anterior pituitary, and the neurointermediate lobe of the pituitary (Hong et al., 1982; Petraglia et al., 1982). Confirming 
a role for androgens, these effects are partially reversed following chronic treatment with testosterone (Petraglia et al., 1982). Similarly, gonadectomized rats exhibit lower beta-endorphin concentrations in plasma, anterior pituitary, neurointermediate lobe, and hypothalamus relative to intact rats (Pluchino et al., 2009). The latter effects are reversed by chronic treatment with testosterone in a dose-dependent manner, but not by the testosterone metabolite, DHT. Chronic administration of exogenous androgens to intact male rats also increases beta-endorphin concentrations. For instance, chronic androgen treatment with the AAS, boldenone undecylenate, 1-de-hydro-17a-methyltestosterone, nandrolone decanoate, and testosterone 17b-cypionate increases beta-endorphin in the midline of thalamus in intact male rats (Harlan et al., 2000). Finally, in intact male rats, chronic treatment with nandrolone significantly increases beta-endorphin concentrations in the ventral tegmental area (Johansson et al., 1997), a region heavily implicated in opioid reinforcement and addiction (Fields \& Margolis, 2015).

Androgens decrease concentrations of beta-endorphin under some, albeit limited, conditions. For instance, chronic treatment with the exogenous androgens, boldenone undecylenate, nandrolone decanoate, and testosterone cypionate, decreases beta-endorphin within the rostral arcuate nucleus (Menard et al., 1994). Moreover, castration increases beta-endorphin concentrations in the medial basal hypothalamus, and this effect is reversed by chronic treatment with testosterone (Wardlaw, 1986). When taken collectively, these latter findings represent exceptions to the general rule that androgens increase concentrations of beta-endorphin in both plasma and tissue.

\subsubsection{Enkephalins}

Similar to their effects on beta-endorphin, androgens increase concentrations of enkephalin peptides in many brain regions. In intact male rats, chronic treatment with nandrolone increases met-enkephalin concentrations in the hypothalamus and striatum (Johansson et al., 2000a) and under some (but not all) conditions in the periaqueductal gray area (cf., Johansson et al., 2000a; 2000b). Intact male rats also have greater concentrations of met- and leu-enkephalin in the anterior pituitary than intact female rats, and castration reduces these concentrations to those observed in females (Hong et al, 1982; Yoshikawa \& Hong, 1983). Chronic administration of the testosterone metabolite, DHT, (but not testosterone) increases concentrations of both met- and leu-enkephalin in the anterior pituitary following castration (Yoshikawa \& Hong, 1983). One exception to these findings is the observation that chronic treatment with testosterone in intact males decreases met- and leu-enkephalin concentrations in the anterior pituitary (Yoshikawa \& Hong, 1983).

\subsubsection{Dynorphin}

Androgens increase concentrations of dynorphin in most brain regions. For instance, chronic treatment with nandrolone significantly increases dynorphin concentrations in the hypothalamus, striatum, and PAG in intact male rats (Johansson et al., 2000a). Similarly, castration decreases dynorphin concentrations in the anterior pituitary (Molineaux et al., 1986; Fullerton et al., 1989), and these decreases can be partially reversed by subchronic (2-day) treatment with testosterone (Molineaux et al., 1986) and fully reversed by chronic (7-day) treatment with DHT (Fullerton et al., 1989).

Interestingly, the nucleus accumbens is an exception to the androgen-induced increase in dynorphin concentrations seen in other brain regions. Chronic treatment with nandrolone significantly decreases dynorphin concentrations in the nucleus accumbens in intact rats (Johansson et al., 2000b). The nucleus accumbens receives dopaminergic afferents from the ventral tegmental area and is a critical structure involved in motivated behavior, drug reinforcement, and addiction. Dynorphin inhibits dopaminergic activity in the nucleus accumbens (Muschamp \& Carlezon, 2013), and androgen-induced reductions in dynorphin should theoretically increase accumbal dopamine concentrations; however, evidence for this possibility is mixed (cf., Birgner et al., 2007; Silva et al., 2009; Triemstra et al., 2008).

Androgen-induced modulations in dynorphin may be explained, in part, by androgen-induced modulations in dynorphin-converting enzyme (DCE). DCE transforms dynorphins into enkephalins via cleavage of the dynorphin peptide (Silberring et al., 1992), and DCE concentrations are under regulatory control by androgens. For example, chronic nandrolone administration significantly decreases DCE concentrations in regions 
that typically exhibit an increase in dynorphin concentrations following androgen treatment, including the caudate putamen, hypothalamus and PAG (Magnusson et al., 2007). In contrast, nandrolone treatment significantly increases DCE concentrations in the nucleus accumbens (Magnusson et al., 2007), which exhibits a significant decrease in dynorphin concentrations following androgen treatment.

\subsubsection{Opioid Receptors}

Early studies using the nonselective opioid ligand, $\left[{ }^{3} \mathrm{H}\right]$ naltrexone, reported that castration increases opioid receptors in whole brain relative to intact male rats, and this effect is reversed by treatment with testosterone propionate (TP; Han \&Fishman, 1979; Han \& Fishman, 1985). Later studies using ligands with greater specificity reported androgenic effects on opioid receptors that differ across subtype and brain region. In some but not all cases, there are sufficient data to compare androgenic effects on both peptide and receptor concentrations to draw functional inferences.

\subsubsection{Mu Receptors}

Androgens decrease mu opioid receptors in neuronal cells across multiple brain regions. In human neuroblastoma cells, mu receptor mRNA decreases following nandrolone treatment, and this effect is fully blocked by simultaneous treatment with an androgenic receptor antagonist (Guarino \& Spampinato, 2008). Androgens also decrease mu opioid receptor protein concentrations in the thalamus and midbrain. Castration increases $\mathrm{mu}$ receptor density in these areas, and this effect is blocked by chronic treatment with testosterone (Takayama et al., 1990, but see Šlamberová et al., 2002 for opposing effects in superior colliculus). Further supporting androgenic decreases in mu opioid receptor density, testosterone-treated castrated rats have lower concentrations of mu receptors in the CA1 and CA3 regions of the hippocampus relative to vehicle-treated castrated rats, and similar effects are observed in the dentate gyrus of castrated rats prenatally exposed to morphine (Šlamberová et al., 2003). Finally, intact male rats exhibit lower mu receptor density in the hypothalamus than intact female rats, and these sex differences are eliminated by either proandrogenic manipulations in females or by antiandrogenic manipulations in males (Limonta et al., 1991). Castration increases mu receptor density in the hypothalamus of male rats, and neonatal testosterone administration slows developmental increases in mu receptor density in the hypothalamus of female rats (Limonta et al., 1991; but see Piva et al., 1987 and Takayma et al., 1990 for examples of null effects of androgens on hypothalamic mu receptors).

Androgen-induced decreases in mu receptor density in some of these areas may be explained, in part, by androgen-induced increases in endogenous beta-endorphin concentrations. Increases in the concentrations of endogenous opioid peptides produce compensatory decreases in opioid receptor density similar to those observed following chronic agonist administration (Bergasa et al., 1992; Hnatowich et al., 1986; Smith \& Yancey, 2003). Consequently, androgenic-induced decreases in mu receptor density in areas such as the midbrain and hypothalamus can be explained, in part, by increased concentrations of beta-endorphin in these regions; however, this does not rule out possible direct effects of androgens on mu receptor mRNA expression or protein synthesis.

It must be noted that androgens increase mu opioid receptor density under some (albeit limited) conditions. For instance, castration prevents inflammation-induced upregulation of mu receptors in the sensory ganglion of the trigeminal nerve, and upregulation is restored following chronic treatment with testosterone (Zhang et al., 2014). Similarly, subchronic treatment with the androgen receptor antagonist, flutamide, prevents inflammation-induced upregulation of mu receptor mRNA in the trigeminal ganglia and dose-dependently blocks the antihyperalgesic effects of a mu opioid agonist in intact male rats (Lee et al., 2017).

\subsubsection{Delta Receptors}

Androgens decrease delta opioid receptor expression in neuronal cells. Nandrolone treatment decreases delta receptor binding and delta receptor mRNA expression in hybrid cell lines naturally expressing delta receptors. Interestingly, these effects are independent of androgen receptors as evidenced by the observation that (1) androgenic decreases in receptor density are observed in a cell line that does not express androgen receptors and (2) androgenic decreases in receptor density are observed in the presence of an androgen re- 
ceptor antagonist (Pasquariello et al., 2000). Androgen-induced decreases in delta opioid receptor density is widespread across brain regions. In rats, for instance, castration increases delta opioid receptor density in the olfactory bulb, thalamus, midbrain, and hypothalamus, and this effect is reversed completely by administration of testosterone (Takayama et al., 1990). Similar to mu receptors, androgen-induced decreases in delta receptors may be explained, in part, by receptor down-regulation induced by androgenic increases in endogenous enkephalin concentrations.

\subsubsection{Kappa Receptors}

Much of what is known about the effects of androgens on kappa receptors is derived from a single investigation. In intact male rats, chronic treatment with nandrolone decreases kappa opioid receptors in most brain regions, with significant decreases observed in the nucleus accumbens shell, hypothalamus, central amygdaloid nucleus, lateral globus pallidus, and stria terminalis (Magnusson et al., 2009). In contrast, chronic nandrolone treatment increases kappa receptor density in the caudate putamen and dorsal endopiriform (Magnusson et al., 2009, also see Ruka et al., 2015 for the effects of castration on hypothalamic brain slices). In most of these regions, androgen-induced decreases in kappa receptor density can be explained, in part, as compensatory responses to androgen-induced increases in endogenous dynorphin concentrations. One notable exception is the nucleus accumbens, which exhibits decreases in both dynorphin concentrations and kappa opioid receptor density following androgenic treatment. As noted above (Section 3.4.1), dynorphin negatively modulates dopamine release in the nucleus accumbens, which is critically involved in motivated behavior and drug addiction. Consequently, androgen-induced decreases in kappa opioid signaling in the nucleus accumbens could account, in part, for the positive-reinforcing and abuse-related effects of AAS in human populations.

\section{Clinical and Public Health Implications}

The observation that androgens may contribute to sex differences in opioid-mediated behaviors has a number of implications for personal and public health. As reviewed above, significant sex differences are apparent in both sensitivity to opioid analgesia and the risk for opioid use disorder. The ability of androgens to amplify (or minimize) these differences has not been sufficiently considered in clinical or public health practice. The data reviewed above point to several possibilities that might guide future decision making in these areas.

\subsection{Implications for Opioid Analgesia}

Converging evidence from preclinical, clinical, and epidemiological studies strongly indicate that women are more sensitive to pain and are more likely to suffer from pain disorders (Section 2.2.1). Some additional evidence also indicates that men are more sensitive to opioid analgesics and typically need lower doses (at least as a function of body weight) to obtain comparable levels of analgesia. A sizeable but underappreciated body of evidence suggests that these sex differences are due, in part, to greater androgenic activity in males. Indeed, preclinical and clinical data suggest that sex differences can be minimized by androgenic blockade in males or androgenic stimulation in females.

One obvious implication of androgen-induced enhancement opioid analgesia is that the effectiveness of opioid analgesics could be increased by direct or indirect activation of androgen receptors. Although clinically intriguing, this practice would have clinically limiting drawbacks for both men and women. In women, for instance, androgens produce masculinizing and anti-feminizing effects, whereas in men, exogenous androgens suppress endogenous androgenic activity, leading to problems with fertility and hypogonadism (Christou et al., 2017; de Souza \& Hallak, 2011; Vorona \& Nieschlag, 2018). Regardless, low levels of endogenous androgenic activity may be an unrecognized contributor to both chronic pain disorders and diminished sensitivity to opioid analgesics. Hypogonadism can quickly be diagnosed by simple blood tests measuring free and total testosterone. Testosterone levels could guide initial dose determinations and subsequent dose adjustments. Moreover, in cases where hypogonadism is detected, opioid treatment could be augmented by androgen treatment to simultaneously decrease pain sensitivity and enhance opioid analgesia.

\subsection{Implications for Opioid Use Disorders}

Men are more likely to use heroin and other illicit opioids, whereas women are more likely to use pres- 
cription opioids and develop an opioid use disorder (Section 2.1.1). Moreover, women are much more likely to experience negative psychosocial consequences from their drug use. These observations are due to many factors, with psychosocial factors likely playing the most prominent role. The role of gonadal hormones in mediating sex differences in opioid use and opioid use disorders has not been extensively examined, and there is a paucity of both preclinical and clinical data looking at the role of androgens. It is nonetheless notable that the abuse of AAS is highly correlated with the abuse of both licit and illicit opioids, suggesting an underappreciated but still unknown relationship between the two pharmacological classes of drugs.

Given that the misuse of AAS is a risk factor for opioid abuse, and similarly, that the misuse of opioids is a risk factor for AAS abuse (Section 3.1.1), drug-abuse prevention programs should utilize early interventions appropriately. An obvious target of these interventions would be adolescent and young adult males, who are mostly likely to misuse AAS and simultaneously misuse both AAS and opioids. It remains to be determined whether androgenic activity can be manipulated to aid in the treatment of opioid use disorders. As mentioned above, administration of direct or indirect agonists at androgen receptors would lead to problematic side effects in the majority of individuals. Androgen receptor antagonists would also be problematic because they produce feminizing effects in cisgender men. Regardless, if opioid intake or opioid seeking is sensitive to androgenic manipulations, some interventions might be feasible. For example, finasteride is a $5 \alpha$-reductase inhibitor used to treat prostatic hyperplasia (i.e., enlarged prostate) and androgenic alopecia (i.e., malepattern baldness) that primarily or exclusively impact men with normal levels of testosterone. Finasteride and other $5 \alpha$-reductase inhibitors do not produce feminizing effects and have limited effects on sexual functioning (Gupta \& Charrette, 2014; Hirshburg et al., 2016; Mella et al., 2010), making them candidates for future clinical trials where potential masculinizing or feminizing effects must be avoided.

\section{Future Directions}

The role of androgens on opioid-mediated behavior is an area that is ripe for further research. There is ample evidence that androgens modulate central concentrations of both endogenous opioid peptides and opioid receptors, and that androgens contribute to reported sex differences in these proteins (Sections 2.4 and 3.4). It is unclear whether the effects of androgens are predominately developmental or activational in nature, whether the effects of androgens differ across age or developmental stage, and the degree to which the central effects of androgens are region specific. All the available data strongly suggest that the effects of androgens are age and region specific, but there are not enough data to create a working model to explain the limited number of empirical observations. The contribution of androgens to sex differences in opioid peptides and receptors is further complicated by the complex role of ovarian hormones on these same proteins in females. Future studies that explicitly explore sex differences must include the estrous cycle as a biological variable.

There is a sizable body of literature suggesting that androgens decrease pain sensitivity and increase opioid analgesia (Section 3.2). Clinical evaluation of testosterone levels, pain tolerance, and optimal dosing parameters are needed to maximize pain management in men with undiagnosed or borderline hypogonadism. In these populations, there are now sufficient data to begin clinical trials with androgen-augmented pain therapies. Such trials need not be limited to androgenic augmentation of opioid analgesics; indeed, androgenic augmentation of nonopioid analgesics may negate the need for opioid analgesia. Even if opioids are necessary, the available data suggest that the dose of opioid could be reduced, thus minimizing problematic side effects such as tolerance and abuse liability.

There is a dearth of information regarding the effects of androgens on opioid reward and reinforcement, particularly in the clinical and human laboratory literature. The available preclinical data are equivocal, and at this time it is difficult to draw conclusions regarding the effects of androgens on the risk for developing a substance use disorder. Although the epidemiological data indicate a clear link between AAS and opioid abuse, evidence of a causal relationship is absent. Preclinical research is perfectly positioned to start systematically examining the role of androgens in opioid reinforcement, including both physiological and supraphysiological concentrations characteristic of AAS abuse. Preclinical studies will need to be conducted in both males and females to determine the contribution of androgens to sex differences in opioids reward 
and reinforcement, taking into consideration the potential influence of ovarian hormones and the estrous cycle. These types of studies will ultimately be needed to determine whether androgenic activity serves as a risk factor (or protective influence) in the likelihood of developing an opioid use disorder.

\section{Conclusions}

Endogenous concentrations of opioid peptides and receptors are under tonic control of circulating androgens. Androgen-induced modulations of these peptides and receptors lead to functional consequences on opioid-mediated behavior. Some of these consequences have clinical relevance, particularly in regard to pain sensitivity, sensitivity to opioid analgesia, and sensitivity to opioid-mediated reward and reinforcement. A greater understanding of how androgens influence these outcomes would lead to better clinical management of both chronic pain and substance use disorders. This review identifies several topics that remain understudied in this area and proposes several lines of research that may carry meaningful translational and public health impact.

\section{Funding and Disclosures}

Role of Funding Source: This work was supported by NIH Grants DA045364, DA031725, and DA045714. The NIH had no role in the writing of the manuscript or in the decision to submit the manuscript for publication.

Contributors: MAS and TP developed the idea. TP and JLS performed the review of the primary literature and wrote the initial drafts. JLS and MS collaborated on writing the final draft. All authors approved the final manuscript.

Acknowledgements: The authors wish to thank Dr. Karl Schmidt for comments on a previous version of this manuscript.

Conflict of Interest: No conflict declared.

\section{References}

Ahangar, N., Kazemi, B., \& Jorjani, M. (2008). Effects of gonadal steroid hormones on GIRK2 gene transcription in the rat central nervous system. Neuroscience letters , 431 (3), 201-205.

al'Absi, M., Wittmers, L. E., Ellestad, D., Nordehn, G., Kim, S. W., Kirschbaum, C., \& Grant, J. E. (2004). Sex differences in pain and hypothalamic-pituitary-adrenocortical responses to opioid blockade. Psychosomatic medicine, 66 (2), 198-206.

Alexander, B. K., Coambs, R. B., \& Hadaway, P. F. (1978). The effect of housing and gender on morphine self-administration in rats. Psychopharmacology , 58 (2), 175-179.

Alexander, G. M., Packard, M. G., \& Hines, M. (1994). Testosterone has rewarding affective properties in male rats: implications for the biological basis of sexual motivation. Behavioral neuroscience, 108 (2), 424.

Aloisi, A. M., Bachiocco, V., Costantino, A., Stefani, R., Ceccarelli, I., Bertaccini, A., \& Meriggiola, M. C. (2007). Cross-sex hormone administration changes pain in transsexual women and men. Pain , 132 , S60-S67.

Aloisi, A. M., Ceccarelli, I., Carlucci, M., Suman, A., Sindaco, G., Mameli, S., .. \& Pari, G. (2011). Hormone replacement therapy in morphine-induced hypogonadic male chronic pain patients. Reproductive Biology and Endocrinology, 9 (1), 1-10.

Aloisi, A. M., Ceccarelli, I., Fiorenzani, P., De Padova, A. M., \& Massafra, C. (2004). Testosterone affects formalin-induced responses differently in male and female rats. Neuroscience Letters , 361 (1-3), 262-264.

AminiLari, M., Manjoo, P., Craigie, S., Couban, R., Wang, L., \& Busse, J. W. (2019). Hormone replacement therapy and opioid tapering for opioid-induced hypogonadism among patients with chronic noncancer pain: a systematic review. Pain Medicine, 20 (2), 301-313. 
Anglin, M. D., Hser, Y. L., \& McGlothlin, W. H. (1987). Sex differences in addict careers. 2. Becoming addicted. The American journal of drug and alcohol abuse , 13 (1-2), 59-71.

Apkhazava, M., Kvachadze, I., Tsagareli, M., Mzhavanadze, D., \& Chakhnashvili, M. (2018). The relationship between thermal pain sensation, free testosterone, Trpv1, Mor levels and various degrees of hostility in young healthy males. Georgian Med News , 283 , 109-14.

Arnedo, M. T., Salvador, A., Martinez-Sanchis, S., \& Gonzalez-Bono, E. (2000). Rewarding properties of testosterone in intact male mice: a pilot study. Pharmacology Biochemistry and Behavior , 65 (2), 327-332.

Arnedo, M. T., Salvador, A., Martínez-Sanchis, S., \& Pellicer, O. (2002). Similar rewarding effects of testosterone in mice rated as short and long attack latency individuals. Addiction biology , 7 (4), 373-379.

Aubrun, F., Salvi, N., Coriat, P., \& Riou, B. (2005). Sex-and age-related differences in morphine requirements for postoperative pain relief. The Journal of the American Society of Anesthesiologists , 103 (1), 156-160.

Back, S. E., Payne, R. L., Simpson, A. N., \& Brady, K. T. (2010). Gender and prescription opioids: Findings from the National Survey on Drug Use and Health. Addictive behaviors , 35 (11), 1001-1007.

Back, S. E., Payne, R. L., Wahlquist, A. H., Carter, R. E., Stroud, Z., Haynes, L., .. \& \& Ling, W. (2011). Comparative profiles of men and women with opioid dependence: results from a national multisite effectiveness trial. The American journal of drug and alcohol abuse , 37 (5), 313-323.

Bai, X., Zhang, X., Li, Y., Lu, L., Li, B., \& He, X. (2015). Sex differences in peripheral mu-opioid receptor mediated analgesia in rat orofacial persistent pain model. PloS one , 10 (3), e0122924.

Barrett, A. C., Cook, C. D., Terner, J. M., Craft, R. M., \& Picker, M. J. (2001). Importance of sex and relative efficacy at the $\mu$ opioid receptor in the development of tolerance and cross-tolerance to the antinociceptive effects of opioids. Psychopharmacology , 158 (2), 154-164.

Barrett, A. C., Cook, C. D., Terner, J. M., Roach, E. L., Syvanthong, C., \& Picker, M. J. (2002). Sex and rat strain determine sensitivity to $x$ opioid-induced antinociception. Psychopharmacology , 160 (2), 170-181.

Bartley, E. J., Palit, S., Kuhn, B. L., Kerr, K. L., Terry, E. L., DelVentura, J. L., \& Rhudy, J. L. (2015). Natural variation in testosterone is associated with hypoalgesia in healthy women. The Clinical journal of pain , 31 (8), 730-739.

Basaria, S., Travison, T. G., Alford, D., Knapp, P. E., Teeter, K., Cahalan, C., .. \& Martel, M. O. (2015). Effects of testosterone replacement in men with opioid-induced androgen deficiency: a randomized controlled trial. Pain , 156 (2), 280.

Bawor, M., Bami, H., Dennis, B. B., Plater, C., Worster, A., Varenbut, M., .. \& Coote, M. (2015b). Testosterone suppression in opioid users: a systematic review and meta-analysis. Drug and alcohol dependence , $149,1-9$.

Bawor, M., Dennis, B. B., Varenbut, M., Daiter, J., Marsh, D. C., Plater, C., .. \& Desai, D. (2015a). Sex differences in substance use, health, and social functioning among opioid users receiving methadone treatment: a multicenter cohort study. Biology of sex differences , 6 (1), 21.

Bayon, A., Shoemaker, W. J., Bloom, F. E., Mauss, A., \& Guillemin, R. (1979). Perinatal development of the endorphin-and enkephalin-containing systems in the rat brain. Brain Research , 179 (1), 93-101.

Becker, J. B., \& Chartoff, E. (2019). Sex differences in neural mechanisms mediating reward and addiction. Neuropsychopharmacology , 44 (1), 166-183.

Becker, J. B., \& Koob, G. F. (2016). Sex differences in animal models: focus on addiction. Pharmacological reviews , 68 (2), 242-263. 
Bergasa, N. V., Rothman, R. B., Vergalla, J., Xu, H., Swain, M. G., \& Jones, E. A. (1992). Central mu-opioid receptors are down-regulated in a rat model of cholestasis. Journal of hepatology, 15 (1-2), 220-224.

Bernal, S. A., Morgan, M. M., \& Craft, R. M. (2007). PAG mu opioid receptor activation underlies sex differences in morphine antinociception. Behavioural brain research , 177 (1), 126-133.

Birgner, C., Kindlundh-Högberg, A. M., Nyberg, F., \& Bergström, L. (2007). Altered extracellular levels of DOPAC and HVA in the rat nucleus accumbens shell in response to sub-chronic nandrolone administration and a subsequent amphetamine challenge. Neuroscience letters , 412 (2), 168-172.

Blick, G., Khera, M., Bhattacharya, R. K., Nguyen, D., Kushner, H., \& Miner, M. M. (2012). Testosterone replacement therapy outcomes among opioid users: the Testim Registry in the United States (TRiUS). Pain Medicine , 13 (5), 688-698.

Bodnar, R. J., \& Kest, B. (2010). Sex differences in opioid analgesia, hyperalgesia, tolerance and withdrawal: central mechanisms of action and roles of gonadal hormones. Hormones and behavior , 58 (1), 72-81.

Borzan, J., \& Fuchs, P. N. (2006). Organizational and activational effects of testosterone on carrageenaninduced inflammatory pain and morphine analgesia. Neuroscience , 143 (3), 885-893.

Bradshaw, H., Miller, J., Ling, Q., Malsnee, K., \& Ruda, M. A. (2000). Sex differences and phases of the estrous cycle alter the response of spinal cord dynorphin neurons to peripheral inflammation and hyperalgesia. Pain , 85 (1-2), 93-99.

Brower, K. J., Blow, F. C., Beresford, T. P., \& Fuelling, C. (1989). Anabolic-androgenic steroid dependence. The Journal of clinical psychiatry . 50 (1), 31-33.

Caldarone, B. J., Stock, H. S., Abrahamsen, G. C., \& Boechler, M. L. (1996). Nonassociative processes and place preferences conditioned by testosterone. The Psychological Record , 46 (2), 373.

Carroll, M. E., Morgan, A. D., Lynch, W. J., Campbell, U. C., \& Dess, N. K. (2002). Intravenous cocaine and heroin self-administration in rats selectively bred for differential saccharin intake: phenotype and sex differences. Psychopharmacology, 161 (3), 304-313.

Cataldo, G., Bernal, S., Markowitz, A., Ogawa, S., Ragnauth, A., Pfaff, D. W., \& Bodnar, R. J. (2005). Organizational manipulation of gonadal hormones and systemic morphine analgesia in female rats: effects of adult ovariectomy and estradiol replacement. Brain research , 1059 (1), 13-19.

Célérier, E., Yazdi, M. T., Castañé, A., Ghozland, S., Nyberg, F., \& Maldonado, R. (2003). Effects of nandrolone on acute morphine responses, tolerance and dependence in mice. European journal of pharmacology , 465 (1-2), 69-81.

Cepeda, M. S., \& Carr, D. B. (2003). Women experience more pain and require more morphine than men to achieve a similar degree of analgesia. Anesthesia 83 Analgesia , 97 (5), 1464-1468.

Cepeda, M. S., Farrar, J. T., Baumgarten, M., Boston, R., Carr, D. B., \& Strom, B. L. (2003). Side effects of opioids during short-term administration: Effect of age, gender, and race. Clinical Pharmacology 83 Therapeutics, 74 (2), 102-112.

Chartoff, E. H., \& Mavrikaki, M. (2015). Sex differences in kappa opioid receptor function and their potential impact on addiction. Frontiers in neuroscience, 9 , 466.

Chia, Y. Y., Chow, L. H., Hung, C. C., Liu, K., Ger, L. P., \& Wang, P. N. (2002). Gender and pain upon movement are associated with the requirements for postoperative patient-controllediv analgesia: a prospective survey of 2,298 Chinese patients. Canadian Journal of Anesthesia , 49 (3), 249.

Christou, M. A., Christou, P. A., Markozannes, G., Tsatsoulis, A., Mastorakos, G., \& Tigas, S. (2017). Effects of anabolic androgenic steroids on the reproductive system of athletes and recreational users: a 
systematic review and meta-analysis. Sports Medicine , 47 (9), 1869-1883. https://doi.org/10.1007/s40279017-0709-z

Cicero, T. J., Aylward, S. C., \& Meyer, E. R. (2003). Gender differences in the intravenous self-administration of mu opiate agonists. Pharmacology Biochemistry and Behavior, 74 (3), 541-549.

Cicero, T. J., Ennis, T., Ogden, J., \& Meyer, E. R. (2000). Gender differences in the reinforcing properties of morphine. Pharmacology Biochemistry and Behavior , 65 (1), 91-96.

Cicero, T. J., Nock, B., \& Meyer, E. R. (1996). Gender-related differences in the antinociceptive properties of morphine. Journal of Pharmacology and Experimental Therapeutics, 279 (2), 767-773.

Cicero, T. J., Nock, B., \& Meyer, E. R. (2002a). Gender-linked differences in the expression of physical dependence in the rat. Pharmacology Biochemistry and Behavior , 72 (3), 691-697.

Cicero, T. J., Nock, B., O'Connor, L., \& Meyer, E. R. (2002b). Role of steroids in sex differences in morphine-induced analgesia: activational and organizational effects. Journal of Pharmacology and Experimental Therapeutics, 300 (2), 695-701.

Cook, C. D., Barrett, A. C., Roach, E. L., Bowman, J. R., \& Picker, M. J. (2000). Sex-related differences in the antinociceptive effects of opioids: importance of rat genotype, nociceptive stimulus intensity, and efficacy at the $\mu$ opioid receptor. Psychopharmacology , 150 (4), 430-442.

Cook, C. J. (1998). Steroidal hormones determine sex-related differences in opioid-induced elevation of nociceptive threshold in sheep (Ovis aries). New Zealand veterinary journal , 46 (2), 68-71.

Cooper, S. E., \& Wood, R. I. (2014). Androgens and opiates: testosterone interaction with morphine self-administration in male rats. Neuroreport, 25 (7), 521.

Craft, R. M. (2008). Sex differences in analgesic, reinforcing, discriminative, and motoric effects of opioids. Experimental and clinical psychopharmacology , 16 (5), 376.

Craft, R. M., \& Bernal, S. A. (2001). Sex differences in opioid antinociception: $x$ and 'mixed action' agonists. Drug and alcohol dependence , 63 (3), 215-228.

Craft, R. M., Clark, J. L., Hart, S. P., \& Pinckney, M. K. (2006). Sex differences in locomotor effects of morphine in the rat. Pharmacology Biochemistry and Behavior , 85 (4), 850-858.

Craft, R. M., Heideman, L. M., \& Bartok, R. E. (1999). Effect of gonadectomy on discriminative stimulus effects of morphine in female versus male rats. Drug and alcohol dependence, 53 (2), 95-109.

Craft, R. M., Kalivas, P. W., \& Stratmann, J. A. (1996). Sex differences in discriminative stimulus effects of morphine in the rat. Behavioural pharmacology .

Craft, R. M., Kruzich, P. J., Boyer, J. S., Harding, J. W., \& Hanesworth, J. M. (1998b). Sex differences in discriminative stimulus and diuretic effects of the $x$ opioid agonist U69, 593 in the rat. Pharmacology Biochemistry and Behavior , 61 (4), 395-403.

Craft, R. M., Morgan, C. L., \& Bernal, S. A. (1998a). Reinforcement frequency, but not gender, determines sensitivity to discriminative stimulus effects of morphine. Behavioural Pharmacology .

Craft, R. M., Stratmann, J. A., Bartok, R. E., Walpole, T. I., \& King, S. J. (1999). Sex differences in development of morphine tolerance and dependence in the rat. Psychopharmacology , 143 (1), 1-7.

Craft, R. M., Ulibarri, C. M., \& Raub, D. J. (2000). Kappa opioid-induced diuresis in female vs. male rats. Pharmacology Biochemistry and Behavior , 65 (1), 53-59.

D'Souza, D. N., Harlan, R. E., \& Garcia, M. M. (2002). Sexually dimorphic effects of morphine and MK-801: sex steroid-dependent and-independent mechanisms. Journal of Applied Physiology , 92 (2), 493-503. 
Dahan, A., Kest, B., Waxman, A. R., \& Sarton, E. (2008). Sex-specific responses to opiates: animal and human studies. Anesthesia \& Analgesia , 107 (1), 83-95.

Daniell, H. W., Lentz, R., \& Mazer, N. A. (2006). Open-label pilot study of testosterone patch therapy in men with opioid-induced androgen deficiency. The Journal of Pain , 7 (3), 200-210.

Darnall, B. D., Stacey, B. R., \& Chou, R. (2012). Medical and psychological risks and consequences of long-term opioid therapy in women. Pain Medicine , 13 (9), 1181-1211.

De Beun, R., Jansen, E., Slangen, J. L., \& Van de Poll, N. E. (1992). Testosterone as appetitive and discriminative stimulus in rats: sex-and dose-dependent effects. Physiology \& behavior , 52 (4), 629-634.

de Souza Silva, M. A., Mattern, C., Topic, B., Buddenberg, T. E., \& Huston, J. P. (2009). Dopaminergic and serotonergic activity in neostriatum and nucleus accumbens enhanced by intranasal administration of testosterone. European Neuropsychopharmacology , 19 (1), 53-63.

de Souza, G. L., \& Hallak, J. (2011). Anabolic steroids and male infertility: a comprehensive review. BJU international , 108 (11), 1860-1865. https://doi.org/10.1111/j.1464-410X.2011.10131.x

Diaz, S. L., Kemmling, A. K., Rubio, M. C., \& Balerio, G. N. (2001). Lack of sex-related differences in the prevention by baclofen of the morphine withdrawal syndrome in mice. Behavioural Pharmacology , 12 (1), 75-79.

Diaz, S. L., Kemmling, A. K., Rubio, M. C., \& Balerio, G. N. (2005). Morphine withdrawal syndrome: involvement of the dopaminergic system in prepubertal male and female mice. Pharmacology Biochemistry and Behavior , 82 (4), 601-607.

DiMeo, A. N., \& Wood, R. I. (2004). Circulating androgens enhance sensitivity to testosterone selfadministration in male hamsters. Pharmacology Biochemistry and Behavior , 79 (2), 383-389.

DiMeo, A. N., \& Wood, R. I. (2006). Self-administration of estrogen and dihydrotestosterone in male hamsters. Hormones and behavior, 49 (4), 519-526.

Drake, C. T., De Oliveira, A. X., Harris, J. A., Connor, D. M., Winkler, C. W., \& Aicher, S. A. (2007). Kappa opioid receptors in the rostral ventromedial medulla of male and female rats. Journal of Comparative Neurology , 500 (3), 465-476.

Dunn, K. E., Weerts, E. M., Huhn, A. S., Schroeder, J. R., Tompkins, D. A., Bigelow, G. E., \& Strain, E. C. (2018). Preliminary evidence of different and clinically meaningful opioid withdrawal phenotypes. Addiction biology, 25 (1), e12680.

Edinger, K. L., \& Frye, C. A. (2004). Testosterone's Analgesic, Anxiolytic, and Cognitive-Enhancing Effects May Be Due in Part to Actions of Its $5 \alpha$-Reduced Metabolites in the Hippocampus. Behavioral neuroscience , $118(6), 1352$.

Edinger, K. L., \& Frye, C. A. (2005). Testosterone's anti-anxiety and analgesic effects may be due in part to actions of its $5 \alpha$-reduced metabolites in the hippocampus. Psychoneuroendocrinology , 30 (5), 418-430.

Elliott, J. C., Picker, M. J., Nelson, C. J., Carrigan, K. A., \& Lysle, D. T. (2003). Sex differences in opioidinduced enhancement of contact hypersensitivity. Journal of investigative dermatology , 121 (5), 1053-1059.

Elliott, J. C., Picker, M. J., Sparrow, A. J., \& Lysle, D. T. (2006). Dissociation between sex differences in the immunological, behavioral, and physiological effects of $x$-and $\delta$-opioids in Fischer rats. Psychopharmacology , 185 (1), 66-75.

Fields, H. L., \& Margolis, E. B. (2015). Understanding opioid reward. Trends in neurosciences , 38 (4), 217-225.

Fillingim, R. B., King, C. D., Ribeiro-Dasilva, M. C., Rahim-Williams, B., \& Riley III, J. L. (2009). Sex, gender, and pain: a review of recent clinical and experimental findings. The journal of pain, 10 (5), 447-485. 
Fillingim, R. B., Ness, T. J., Glover, T. L., Campbell, C. M., Hastie, B. A., Price, D. D., \& Staud, R. (2005). Morphine responses and experimental pain: sex differences in side effects and cardiovascular responses but not analgesia. The Journal of Pain , 6 (2), 116-124.

Fillingim, R. B., Ness, T. J., Glover, T. L., Campbell, C. M., Price, D. D., \& Staud, R. (2004). Experimental pain models reveal no sex differences in pentazocine analgesia in humans. Anesthesiology: The Journal of the American Society of Anesthesiologists , 100 (5), 1263-1270.

Flores, C. A., Shughrue, P., Petersen, S. L., \& Mokha, S. S. (2003). Sex-related differences in the distribution of opioid receptor-like 1 receptor mRNA and colocalization with estrogen receptor mRNA in neurons of the spinal trigeminal nucleus caudalis in the rat. Neuroscience, 118 (3), 769-778.

Frye, C. A., Rhodes, M. E., Rosellini, R., \& Svare, B. (2002). The nucleus accumbens as a site of action for rewarding properties of testosterone and its $5 \alpha$-reduced metabolites. Pharmacology Biochemistry and Behavior, 74 (1), 119-127.

Fullerton, M. J., Smith, A. I., Clements, J. A., \& Funder, J. W. (1989). Gonadal steroids and anterior lobe dynorphin in the male rat. Journal of steroid biochemistry , 32 (2), 303-308.

Gårevik, N., \& Rane, A. (2010). Dual use of anabolic-androgenic steroids and narcotics in Sweden. Drug and Alcohol Dependence , 109 (1-3), 144-146.

Giacomuzzi, S. M., Riemer, Y., Ertl, M., Kemmler, G., Rössler, H., Hinterhuber, H., \& Kurz, M. (2005). Gender differences in health-related quality of life on admission to a maintenance treatment program. European Addiction Research , 11 (2), 69-75.

Glintborg, D., Vaegter, H. B., Christensen, L. L., Bendix, E., Graven-Nielsen, T., Andersen, P. G., \& Andersen, M. (2020). Testosterone replacement therapy of opioid-induced male hypogonadism improved body composition but not pain perception: a double-blind, randomized, and placebo-controlled trial. European Journal of Endocrinology, 182 (6), 539-548.

Green, T. C., Serrano, J. M. G., Licari, A., Budman, S. H., \& Butler, S. F. (2009). Women who abuse prescription opioids: Findings from the Addiction Severity Index-Multimedia Version@ Connect prescription opioid database. Drug and alcohol dependence, 103 (1-2), 65-73.

Greenfield, S. F., Brooks, A. J., Gordon, S. M., Green, C. A., Kropp, F., McHugh, R. K., .. \& Miele, G. M. (2007). Substance abuse treatment entry, retention, and outcome in women: A review of the literature. Drug and alcohol dependence, 86 (1), 1-21.

Guarino, G., \& Spampinato, S. (2008). Nandrolone decreases mu opioid receptor expression in SH-SY5Y human neuroblastoma cells. Neuroreport, 19 (11), 1131-1135.

Gupta, A. K., \& Charrette, A. (2014). The efficacy and safety of $5 \alpha$-reductase inhibitors in androgenetic alopecia: a network meta-analysis and benefit-risk assessment of finasteride and dutasteride. Journal of dermatological treatment, 25 (2), 156-161.

Hahn, E. F., \& Fishman, J. (1979). Changes in rat brain opiate receptor content upon castration and testosterone replacement. Biochemical and biophysical research communications, 90 (3), 819-823.

Hahn, E. F., \& Fishman, J. (1985). Castration affects male rat brain opiate receptor content. Neuroendocrinology , 41 (1), 60-63.

Harlan, R. E., Brown, H. E., Lynch, C. S., D'Souza, D., \& Garcia, M. M. (2000). Androgenic-anabolic steroids blunt morphine-induced c-fos expression in the rat striatum: possible role of $\beta$-endorphin. Brain research, 853 (1), 99-104.

Harris, J. A., Chang, P. C., \& Drake, C. T. (2004). Kappa opioid receptors in rat spinal cord: sex-linked distribution differences. Neuroscience, 124 (4), 879-890. 
Hirshburg, J. M., Kelsey, P. A., Therrien, C. A., Gavino, A. C., \& Reichenberg, J. S. (2016). Adverse effects and safety of 5-alpha reductase inhibitors (finasteride, dutasteride): a systematic review. The Journal of clinical and aesthetic dermatology, 9 (7), 56-62.

Hnatowich, M. R., Labella, F. S., Kiernan, K., \& Glavin, G. B. (1986). Cold-restraint stress reduces [3H] etorphine binding to rat brain membranes: Influence of acute and chronic morphine and naloxone. Brain research , 380 (1), 107-113.

Ho, K. W. (2019). Opioid-induced androgen deficiency (OPIAD): prevalence, consequence, and efficacy of testosterone replacement. Current Opinion in Endocrine and Metabolic Research , 6 , 54-59.

Hochberg, Z. E., Pacak, K., \& Chrousos, G. P. (2003). Endocrine withdrawal syndromes. Endocrine reviews , 24 (4), 523-538.

Holtman Jr, J. R., \& Wala, E. P. (2005). Characterization of morphine-induced hyperalgesia in male and female rats. Pain, 114 (1-2), 62-70.

Holtman Jr, J. R., Sloan, J. W., \& Wala, E. P. (2004). Morphine tolerance in male and female rats. Pharmacology Biochemistry and Behavior, 77 (3), 517-523.

Hong, J. S., Yoshikawa, K., \& Lamartiniere, C. A. (1982). Sex-related difference in the rat pituitary [Met5]enkephalin level-altered by gonadectomy. Brain Research , 251 (2), 380-383.

Hser, Y. I., Anglin, M. D., \& Booth, M. W. (1987). Sex differences in addict careers. 3. Addiction. The American journal of drug and alcohol abuse, 13 (3), 231-251.

Huang, E. Y. K., Chen, Y. H., Huang, T. Y., Chen, Y. J., \& Chow, L. H. (2016). Chronic administration of nandrolone increases susceptibility to morphine dependence without correlation with LVV-hemorphin 7 in rats. Neuropeptides , 59, 63-69.

Huhn, A. S., Berry, M. S., \& Dunn, K. E. (2018). Systematic review of sex-based differences in opioid-based effects. International Review of Psychiatry, 30 (5), 107-116.

Huhn, A. S., Berry, M. S., \& Dunn, K. E. (2019). Sex-Based Differences in Treatment Outcomes for Persons With Opioid Use Disorder. The American journal on addictions , 28 (4), 246-261.

Islam, A. K., Cooper, M. L., \& Bodnar, R. J. (1993). Interactions among aging, gender, and gonadectomy effects upon morphine antinociception in rats. Physiology \&3 Behavior , 54 (1), 45-53.

Johansson, P., Hallberg, M., Kindlundh, A., \& Nyberg, F. (2000a). The effect on opioid peptides in the rat brain, after chronic treatment with the anabolic androgenic steroid, nandrolone decanoate. Brain research bulletin , 51 (5), 413-418.

Johansson, P., Lindqvist, A. S., Nyberg, F., \& Fahlke, C. (2000b). Anabolic androgenic steroids affects alcohol intake, defensive behaviors and brain opioid peptides in the rat. Pharmacology Biochemistry and Behavior , 67 (2), 271-279.

Johansson, P., Ray, A., Zhou, Q., Huang, W., Karlsson, K., \& Nyberg, F. (1997). Anabolic androgenic steroids increase $\beta$-endorphin levels in the ventral tegmental area in the male rat brain. Neuroscience research , $27(2), 185-189$.

Johnson, L. R., \& Wood, R. I. (2001). Oral testosterone self-administration in male hamsters. Neuroendocrinology, 73 (4), 285-292.

Kanayama, G., Brower, K. J., Wood, R. I., Hudson, J. I., \& Pope Jr, H. G. (2010). Treatment of anabolicandrogenic steroid dependence: Emerging evidence and its implications. Drug and alcohol dependence, 109 (1-3), 6-13.

Kanayama, G., Brower, K. J., Wood, R. I., Hudson, J. I., \& Pope Jr, H. G. (2009a). Anabolic-androgenic steroid dependence: an emerging disorder. Addiction , 104 (12), 1966-1978. 
Kanayama, G., Cohane, G. H., Weiss, R. D., \& Pope, H. G. (2003). Past anabolic-androgenic steroid use among men admitted for substance abuse treatment: an underrecognized problem?. The Journal of clinical psychiatry , 64 (2), 156-160.

Kanayama, G., Hudson, J. I., \& Pope Jr, H. G. (2009b). Features of men with anabolic-androgenic steroid dependence: a comparison with nondependent AAS users and with AAS nonusers. Drug and alcohol dependence, 102 (1-3), 130-137.

Kanayama, G., Pope Jr, H. G., \& Hudson, J. I. (2018). Associations of anabolic-androgenic steroid use with other behavioral disorders: an analysis using directed acyclic graphs. Psychological Medicine , 48 (15), 2601-2608.

Kaplovitch, E., Gomes, T., Camacho, X., Dhalla, I. A., Mamdani, M. M., \& Juurlink, D. N. (2015). Sex differences in dose escalation and overdose death during chronic opioid therapy: a population-based cohort study. PloS one, 10 (8), e0134550.

Karami, M., \& Zarrindast, M. R. (2008). Morphine sex-dependently induced place conditioning in adult Wistar rats. European journal of pharmacology , 582 (1-3), 78-87.

Kashkin, K. B., \& Kleber, H. D. (1989). Hooked on hormones?: An anabolic steroid addiction hypothesis. Jama, 262 (22), 3166-3170.

Kasson, B. G., \& George, R. (1984). Endocrine influences on the actions of morphine: IV. Effects of sex and strain. Life sciences, 34 (17), 1627-1634.

Kavaliers, M., \& Innes, D. G. (1987). Sex and day-night differences in opiate-induced responses of insular wild deer mice, Peromyscus maniculatus triangularis. Pharmacology Biochemistry and Behavior , 27 (3), 477-482.

Kepler, K. L., Kest, B., Kiefel, J. M., Cooper, M. L., \& Bodnar, R. J. (1989). Roles of gender, gonadectomy and estrous phase in the analgesic effects of intracerebroventricular morphine in rats. Pharmacology Biochemistry and Behavior, 34 (1), 119-127.

Kest, B., Adler, M., \& Hopkins, E. (2000). Sex differences in thermoregulation after acute and chronic morphine administration in mice. Neuroscience letters , 291 (2), 126-128.

Kest, B., Wilson, S. G., \& Mogil, J. S. (1999). Sex differences in supraspinal morphine analgesia are dependent on genotype. Journal of Pharmacology and Experimental Therapeutics , 289 (3), 1370-1375.

Kindlundh, A. M., Isacson, D. G., Berglund, L., \& Nyberg, F. (1999). Factors associated with adolescent use of doping agents: anabolic-androgenic steroids. Addiction , 94 (4), 543-553.

King, B. E., Packard, M. G., \& Alexander, G. M. (1999). Affective properties of intra-medial preoptic area injections of testosterone in male rats. Neuroscience letters , 269 (3), 149-152.

Kokane, S. S., \& Perrotti, L. I. (2020). Sex Differences and the Role of Estradiol in Mesolimbic Reward Circuits and Vulnerability to Cocaine and Opiate Addiction. Frontiers in Behavioral Neuroscience, 14.

Kren, M. C., Haller, V. L., \& Welch, S. P. (2008). The role of gonadal hormones on opioid receptor protein density in arthritic rats. European journal of pharmacology , 578 (2-3), 177-184.

Krzanowska, E. K., \& Bodnar, R. J. (1999). Morphine antinociception elicited from the ventrolateral periaqueductal gray is sensitive to sex and gonadectomy differences in rats. Brain research , 821 (1), 224-230.

Krzanowska, E. K., Ogawa, S., Pfaff, D. W., \& Bodnar, R. J. (2002). Reversal of sex differences in morphine analgesia elicited from the ventrolateral periaqueductal gray in rats by neonatal hormone manipulations. Brain research, 929 (1), 1-9.

Kuhn, C. (2015). Emergence of sex differences in the development of substance use and abuse during adolescence. Pharmacology 83 therapeutics , 153 , 55-78. 
Lacy, R. T., Strickland, J. C., Feinstein, M. A., Robinson, A. M., \& Smith, M. A. (2016). The effects of sex, estrous cycle, and social contact on cocaine and heroin self-administration in rats. Psychopharmacology , 233 (17), 3201-3210.

Lee, C. W. S., \& Ho, K. (2013). Sex differences in opioid analgesia and addiction: interactions among opioid receptors and estrogen receptors. Molecular pain , 9 (1), 45.

Lee, K. S., Zhang, Y., Asgar, J., Auh, Q. S., Chung, M. K., \& Ro, J. Y. (2016). Androgen receptor transcriptionally regulates $\mu$-opioid receptor expression in rat trigeminal ganglia. Neuroscience , 331 , 52-61.

Limonta, P., Dondi, D., Maggi, R., \& Piva, F. (1991). Testosterone and postnatal ontogenesis of hypothalamic $\mu$ ([3H] dihydromorphine) opioid receptors in the rat. Developmental brain research ,62 (1), 131-136.

Lopresti, N. M., Esguerra, M., \& Mermelstein, P. G. (2020). Sex Differences in Animal Models of Opioid Reward. Current Sexual Health Reports, 1-9.

Loyd, D. R., \& Murphy, A. Z. (2014). The neuroanatomy of sexual dimorphism in opioid analgesia. Experimental neurology , 259, 57-63.

Loyd, D. R., Wang, X., \& Murphy, A. Z. (2008). Sex differences in $\mu$-opioid receptor expression in the rat midbrain periaqueductal gray are essential for eliciting sex differences in morphine analgesia. Journal of neuroscience, 28 (52), 14007-14017.

Lynch, W. J., \& Carroll, M. E. (1999). Sex differences in the acquisition of intravenously self-administered cocaine and heroin in rats. Psychopharmacology , 144 (1), 77-82.

Maggi, R., Limonta, P., Dondi, D., \& Piva, F. (1991). Modulation of the binding characteristics of hypothalamic mu opioid receptors in rats by gonadal steroids. The Journal of steroid biochemistry and molecular biology , 40 (1-3), 113-121.

Magnusson, K., Birgner, C., Bergström, L., Nyberg, F., \& Hallberg, M. (2009). Nandrolone decanoate administration dose-dependently affects the density of kappa opioid peptide receptors in the rat brain determined by autoradiography. Neuropeptides , 43 (2), 105-111.

Magnusson, K., Hallberg, M., Bergquist, J., \& Nyberg, F. (2007). Enzymatic conversion of dynorphin A in the rat brain is affected by administration of nandrolone decanoate. Peptides , 28 (4), 851-858.

Mavrikaki, M., Pravetoni, M., Page, S., Potter, D., \& Chartoff, E. (2017). Oxycodone self-administration in male and female rats. Psychopharmacology , 234 (6), 977-987.

Mazid, S., Hall, B. S., Odell, S. C., Stafford, K., Dyer, A. D., Van Kempen, T. A., .. \& \& Milner, T. A. (2016). Sex differences in subcellular distribution of delta opioid receptors in the rat hippocampus in response to acute and chronic stress. Neurobiology of Stress , 5 , 37-53.

McBride, A. J., Williamson, K., \& Petersen, T. (1996). Three cases of nalbuphine hydrochloride dependence associated with anabolic steroid use. British journal of sports medicine, 30 (1), 69-70.

McHugh, R. K., Votaw, V. R., Sugarman, D. E., \& Greenfield, S. F. (2018). Sex and gender differences in substance use disorders. Clinical psychology review , 66 , 12-23.

Mella, J. M., Perret, M. C., Manzotti, M., Catalano, H. N., \& Guyatt, G. (2010). Efficacy and safety of finasteride therapy for androgenetic alopecia: a systematic review. Archives of dermatology , 146 (10), 11411150 .

Menard, C. S., Hebert, T. J., Dohanich, G. P., \& Harlan, R. E. (1995). Androgenic-anabolic steroids modify $\beta$-endorphin immunoreactivity in the rat brain. Brain research , 669 (2), 255-262.

Mhillaj, E., Morgese, M. G., Tucci, P., Bove, M., Schiavone, S., \& Trabace, L. (2015). Effects of anabolicandrogens on brain reward function. Frontiers in neuroscience, 9 , 295. 
Mogil, J. S. (2020). Qualitative sex differences in pain processing: emerging evidence of a biased literature. Nature Reviews Neuroscience, 1-13.

Molineaux, C. J., Hassen, A. H., Rosenberger, J. G., \& Cox, B. M. (1986). Response of rat pituitary anterior lobe prodynorphin products to changes in gonadal steroid environment. Endocrinology , 119 (5), 2297-2305.

Moran, L. M., Kowalczyk, W. J., Phillips, K. A., Vahabzadeh, M., Lin, J. L., Mezghanni, M., .. \& Preston, K. L. (2018). Sex differences in daily life stress and craving in opioid-dependent patients. The American journal of drug and alcohol abuse, 44 (5), 512-523.

Morley-Fletcher, S., Palanza, P., Parolaro, D., Viganò, D., \& Laviola, G. (2003). Intrauterine position has long-term influence on brain $\mu$-opioid receptor density and behaviour in mice. Psychoneuroendocrinology, 28 (3), 386-400.

Mousavi, Z., Shafaghi, B., Kobarfard, F., \& Jorjani, M. (2007). Sex differences and role of gonadal hormones on glutamate level in the nucleus accumbens in morphine tolerant rats: a microdialysis study. European journal of pharmacology , 554 (2-3), 145-149.

Muschamp, J. W., \& Carlezon, W. A. (2013). Roles of nucleus accumbens CREB and dynorphin in dysregulation of motivation. Cold Spring Harbor perspectives in medicine , 3 (2), a012005.

Nasser, S. A., \& Afify, E. A. (2019). Sex differences in pain and opioid mediated antinociception: Modulatory role of gonadal hormones. Life sciences, 237, 116926.

Nayebi, A. R. M., \& Rezazadeh, H. (2008). Effect of testosterone on morphine withdrawal syndrome in rats. Asian journal of andrology, 10 (5), 765-769.

NIDA. 2020, May 28. Sex and Gender Differences in Substance Use. Retrieved from https://www.drugabuse.gov/publications/research-reports/substance-use-in-women/sex-gender-differencesin-substance-use on 2020, September 24

Negus, S. S., \& Mello, N. K. (2002). Effects of gonadal steroid hormone treatments on opioid antinociception in ovariectomized rhesus monkeys. Psychopharmacology , 159 (3), 275-283.

Negus, S. S., Pope Jr, H. G., Kanayama, G., Wines Jr, J. D., \& Fischer, B. D. (2001). Lack of evidence for opioid tolerance or dependence in rhesus monkeys following high-dose anabolic-androgenic steroid administration. Psychoneuroendocrinology, 26 (8), 789-796.

Niesters, M., Dahan, A., Kest, B., Zacny, J., Stijnen, T., Aarts, L., \& Sarton, E. (2010). Do sex differences exist in opioid analgesia? A systematic review and meta-analysis of human experimental and clinical studies. Pain, 151 (1), 61-68.

Nyberg, F., \& Hallberg, M. (2012). Interactions between opioids and anabolic androgenic steroids: implications for the development of addictive behavior. Int Rev Neurobiol , 102 , 189-206.

O'Rourke, T. K., \& Wosnitzer, M. S. (2016). Opioid-induced androgen deficiency (OPIAD): diagnosis, management, and literature review. Current urology reports , 17 (10), 76.

Packard, M. G., Cornell, A. H., \& Alexander, G. M. (1997). Rewarding affective properties of intra-nucleus accumbens injections of testosterone. Behavioral neuroscience, 111 (1), 219.

Padnekar, J. R., \& Mulgaonker, V. K. (1995). Role of testosterone on pain threshold in rats. Indian journal of physiology and pharmacology , 39 , 423-424.

Papaleo, F., \& Contarino, A. (2006). Gender-and morphine dose-linked expression of spontaneous somatic opiate withdrawal in mice. Behavioural brain research , 170 (1), 110-118.

Pasquariello, A., Di Toro, R., Nyberg, F., \& Spampinato, S. (2000). Down-regulation of delta opioid receptor mRNA by an anabolic steroid in neuronal hybrid cells. Neuroreport, 11 (4), 863-867. 
Peckham, E. M., Graves, S. M., Jutkiewicz, E., Becker, J. B., \& Traynor, J. R. (2011). Role of gonadal hormones on mu-opioid-stimulated [35 S] GTP $\gamma \mathrm{S}$ binding and morphine-mediated antinociception in male and female Sprague-Dawley rats. Psychopharmacology , 218 (3), 483-492.

Peters, K. D., \& Wood, R. I. (2004). Androgen dependence in hamsters: overdose, tolerance, and potential opioidergic mechanisms. Neuroscience, 130 (4), 971-981.

Petraglia, F., Penalva, A., Locatelli, V. A., Cocchi, D., Panerai, A. E., Genazzani, A. R., \& Müller, E. E. (1982). Effect of gonadectomy and gonadal steroid replacement on pituitary and plasma $\beta$-endorphin levels in the rat. Endocrinology , 111 (4), 1224-1229.

Philipova, T., Ivanova, T., Pavlova, E., Kasakov, L., \& Vlaskovska, M. (2003). Nandrolone modulates the non-opioid and opioid analgesia and tolerance/dependence: role of sexual dimorphism. Archives of Physiology and Biochemistry , 111 (5), 429-436.

Piva, F., Maggi, R., Limonta, P., Dondi, D., \& Martini, L. (1987). Decrease of mu opioid receptors in the brain and in the hypothalamus of the aged male rat. Life sciences , 40 (4), 391-398.

Pluchino, N., Ninni, F., Casarosa, E., Giannini, A., Merlini, S., Cubeddu, A., .. \& \& Genazzani, A. R. (2009). Sex differences in brain and plasma $\beta$-endorphin content following testosterone, dihydrotestosterone and estradiol administration to gonadectomized rats. Neuroendocrinology , 89 (4), 411-423.

Quock, R. M., Vaughn, L. K., Barlament, J., \& Wojcechowskyj, J. A. (1985). Sex and strain differences in morphine-induced temperature effects in WKYs and SHRs. Brain research bulletin , 14 (4), 323-326.

Raheem, O. A., Patel, S. H., Sisul, D., Furnish, T. J., \& Hsieh, T. C. (2017). The role of testosterone supplemental therapy in opioid-induced hypogonadism: a retrospective pilot analysis. American journal of men's health , 11 (4), 1208-1213.

Ranjan, R., Parmar, A., Pattanayak, R. D., \& Dhawan, A. (2014). Dependence on anabolic-androgenic steroids: a case report and brief review. Delhi Psychiatry J , 17 (2), 481-4.

Rasakham, K., \& Liu-Chen, L. Y. (2011). Sex differences in kappa opioid pharmacology. Life sciences , 88 (1-2), 2-16.

Reisine, T. (1995). Opiate receptors. Neuropharmacology,34 (5), 463-472. doi:10.1016/0028-3908(95)000252

Rimanóczy, A., \& Vathy, I. (1995). Prenatal exposure to morphine alters brain $\mu$ opioid receptor characteristics in rats. Brain research , 690 (2), 245-248.

Roantree, E., \& Zylicz, Z. (2009). Opioid-induced hypogonadism in palliative care. Does it matter? Report on four patients treated with hormone substitution. Advances in Palliative Medicine , 8 (2), 69-74.

Ruka, K. A., Burger, L. L., \& Moenter, S. M. (2016). Both estrogen and androgen modify the response to activation of neurokinin- 3 and $x$-opioid receptors in arcuate kisspeptin neurons from male mice. Endocrinology , 157 (2), 752-763.

Sadeghi, M., Sianati, S., Anaraki, D. K., Ghasemi, M., Paydar, M. J., Sharif, B., ... \& Dehpour, A. R. (2009). Study of morphine-induced dependence in gonadectomized male and female mice. Pharmacology Biochemistry and Behavior, 91 (4), 604-609.

Sarton, E., Olofsen, E., Romberg, R., den Hartigh, J., Kest, B., Nieuwenhuijs, D., .. \& Dahan, A. (2000). Sex differences in morphine analgesiaan experimental study in healthy volunteers. Anesthesiology: The Journal of the American Society of Anesthesiologists , 93 (5), 1245-1254.

Schieber LZ, Guy GP Jr, Seth P, Losby JL. Variation in Adult Outpatient Opioid Prescription Dispensing by Age and Sex — United States, 2008-2018. MMWR Morb Mortal Wkly Rep 2020;69:298-302. DOI: http://dx.doi.org/10.15585/mmwr.mm6911a5 
Serdarevic, M., Striley, C. W., \& Cottler, L. B. (2017). Gender differences in prescription opioid use. Current opinion in psychiatry, 30 (4), 238.

Sharma, D. K., Singh, N. K., Goyal, A., Gupta, J. K., \& Yadav, H. N. (2019). Role of Testosterone in Swimming Exercise-induced Analgesia in Rats. Indian journal of pharmaceutical education and research , 53 (4), 675-681.

Silberring, J., Castello, M. E., \& Nyberg, F. (1992). Characterization of dynorphin A-converting enzyme in human spinal cord. An endoprotease related to a distinct conversion pathway for the opioid heptadecapeptide?. Journal of Biological Chemistry , 267 (30), 21324-21328.

Simerly, R. B. (1991). Prodynorphin and proenkephalin gene expression in the anteroventral periventricular nucleus of the rat: sexual differentiation and hormonal regulation. Molecular and Cellular Neuroscience, 2 (6), 473-484.

Skarberg, K., Nyberg, F., \& Engstrom, I. (2009). Multisubstance use as a feature of addiction to anabolicandrogenic steroids. European Addiction Research , 15 (2), 99-106.

Šlamberová, R., Rimanóczy, A., Bar, N., Schindler, C. J., \& Vathy, I. (2003). Density of $\mu$-opioid receptors in the hippocampus of adult male and female rats is altered by prenatal morphine exposure and gonadal hormone treatment. Hippocampus , 13 (4), 461-471.

Šlamberová, R., Rimanóczy, Á., Riley, M. A., Schindler, C. J., \& Vathy, I. (2002). Mu-opioid receptors in seizure-controlling brain structures are altered by prenatal morphine exposure and by male and female gonadal steroids in adult rats. Brain research bulletin , 58 (4), 391-400.

Smith, M. A., \& Yancey, D. L. (2003). Sensitivity to the effects of opioids in rats with free access to exercise wheels: $\mu$-opioid tolerance and physical dependence. Psychopharmacology , 168 (4), 426-434.

South, S. M., Wright, A. W., Lau, M., Mather, L. E., \& Smith, M. T. (2001). Sex-related differences in antinociception and tolerance development following chronic intravenous infusion of morphine in the rat: modulatory role of testosterone via morphine clearance. Journal of Pharmacology and Experimental Therapeutics , 297 (1), 446-457.

Stewart, J., \& Rodaros, D. (1999). The effects of gonadal hormones on the development and expression of the stimulant effects of morphine in male and female rats. Behavioural brain research , 102 (1-2), 89-98.

Stoffel, E. C., Ulibarri, C. M., \& Craft, R. M. (2003). Gonadal steroid hormone modulation of nociception, morphine antinociception and reproductive indices in male and female rats. Pain, 103 (3), 285-302.

Stoffel, E. C., Ulibarri, C. M., Folk, J. E., Rice, K. C., \& Craft, R. M. (2005). Gonadal hormone modulation of mu, kappa, and delta opioid antinociception in male and female rats. The Journal of Pain , 6 (4), 261-274.

Sumner, J. E., Ulibarri, C., \& Craft, R. M. (2006). Testosterone modulation of reproductive indices vs. morphine antinociception in male rats. Life sciences , 79 (22), 2119-2127.

Takayama, H., Ogawa, N., Asanuma, M., \& Ota, Z. (1990). Regional responses of rat brain opioid receptors upon castration and testosterone replacement. Research communications in chemical pathology and pharmacology , 70 (3), 355-358.

Tang, F., \& Man, W. S. Y. (1991). The regional distribution of thyrotropin releasing hormone, leuenkephalin, met-enkephalin, substance $\mathrm{P}$, somatostatin and cholecystokinin in the rat brain and pituitary. Neuropeptides, 19 (4), 287-292.

Teepker, M., Peters, M., Vedder, H., Schepelmann, K., \& Lautenbacher, S. (2010). Menstrual variation in experimental pain: correlation with gonadal hormones. Neuropsychobiology , 61 (3), 131-140.

Terner, J. M., Barrett, A. C., Cook, C. D., \& Picker, M. J. (2003). Sex differences in (-)-pentazocine antinociception: comparison to morphine and spiradoline in four rat strains using a thermal nociceptive 
assay. Behavioural pharmacology , 14 (1), 77-85.

Terner, J. M., Barrett, A. C., Grossell, E., \& Picker, M. J. (2002). Influence of gonadectomy on the antinociceptive effects of opioids in male and female rats. Psychopharmacology , 163 (2), 183-193.

Terner, J. M., Barrett, A. C., Lomas, L. M., Negus, S. S., \& Picker, M. J. (2006). Influence of low doses of naltrexone on morphine antinociception and morphine tolerance in male and female rats of four strains. Pain , $122(1-2), 90-101$.

Tershner, S. A., Mitchell, J. M., \& Fields, H. L. (2000). Brainstem pain modulating circuitry is sexually dimorphic with respect to mu and kappa opioid receptor function. Pain , 85 (1-2), 153-159.

Trenton, A. J., \& Currier, G. W. (2005). Behavioural manifestations of anabolic steroid use. CNS drugs , 19 (7), 571-595.

Triemstra, J. L., Sato, S. M., \& Wood, R. I. (2008). Testosterone and nucleus accumbens dopamine in the male Syrian hamster. Psychoneuroendocrinology , 33 (3), 386-394.

Tsutsui, K. T., Wood, R. I., \& Craft, R. M. (2011). Anabolic-androgenic steroid effects on nociception and morphine antinociception in male rats. Pharmacology Biochemistry and Behavior, 99 (3), 500-508.

Van Kempen, T. A., Kahlid, S., Gonzalez, A. D., Spencer-Segal, J. L., Tsuda, M. C., Ogawa, S., .. \& Milner, T. A. (2013). Sex and estrogen receptor expression influence opioid peptide levels in the mouse hippocampal mossy fiber pathway. Neuroscience letters , 552, 66-70.

Velásquez, V. B., Zamorano, G. A., Martínez-Pinto, J., Bonansco, C., Jara, P., Torres, G. E., ... \& Sotomayor-Zárate, R. (2019). Programming of dopaminergic neurons by early exposure to sex hormones: effects on morphine-induced accumbens dopamine release, reward, and locomotor behavior in male and female rats. Frontiers in Pharmacology , 10 , 295.

Verdi, J., \& Ahmadiani, A. (2007). Finasteride, a $5 \alpha$-reductase inhibitor, potentiates antinociceptive effects of morphine, prevents the development of morphine tolerance and attenuates abstinence behavior in the rat. Hormones and Behavior, 51 (5), 605-610.

Vorona, E., \& Nieschlag, E. (2018). Adverse effects of doping with anabolic androgenic steroids in competitive athletics, recreational sports and bodybuilding. Minerva endocrinologica , 43 (4), 476-488. https://doi.org/10.23736/S0391-1977.18.02810-9

Wardlaw, S. L. (1986). Regulation of $\beta$-Endorphin, Corticotropin-Like Intermediate Lobe Peptide, and $\alpha$-Melanotropin Stimulating Hormone in the Hypothalamus by Testosterone. Endocrinology , 119 (1), 19-24.

Watson Jr, R. E., Hoffmann, G. E., \& Wiegand, S. J. (1986). Sexually dimorphic opioid distribution in the preoptic area: manipulation by gonadal steroids. Brain research , 398 (1), 157-163.

White, D. A., Michaels, C. C., \& Holtzman, S. G. (2008). Periadolescent male but not female rats have higher motor activity in response to morphine than do adult rats. Pharmacology Biochemistry and Behavior , 89 (2), 188-199.

Williams, T. J., Torres-Reveron, A., Chapleau, J. D., \& Milner, T. A. (2011). Hormonal regulation of delta opioid receptor immunoreactivity in interneurons and pyramidal cells in the rat hippocampus. Neurobiology of learning and memory, 95 (2), 206-220.

Wilson N, Kariisa M, Seth P, Smith H IV, Davis NL. Drug and Opioid-Involved Overdose Deaths - United States, 2017-2018. MMWR Morb Mortal Wkly Rep 2020;69:290-297. DOI: http://dx.doi.org/10.15585/mmwr.mm6911a4

Wilson, M. A., Mascagni, F., \& McDonald, A. J. (2002). Sex differences in delta opioid receptor immunoreactivity in rat medial amygdala. Neuroscience letters , 328 (2), 160-164. 
Wines, J., Gruber, A., Pope, H., \& Lukas, S. (1999). Nalbuphine hydrochloride dependence in anabolic steroid users. American Journal on Addictions , 8 (2), 161-164.

Wood, R. I. (2006). Anabolic steroids: a fatal attraction?. Journal of neuroendocrinology, 18 (3), 227-228.

Wood, R. I. (2008). Anabolic-androgenic steroid dependence? Insights from animals and humans. Frontiers in neuroendocrinology, 29 (4), 490-506.

Wood, R. I., Johnson, L. R., Chu, L., Schad, C., \& Self, D. W. (2004). Testosterone reinforcement: intravenous and intracerebroventricular self-administration in male rats and hamsters. Psychopharmacology , 171 (3), 298-305.

Wood, R. I., Vertelkina, N. V., \& Antzoulatos, E. (2011). Testosterone as a discriminative stimulus in male rats. Pharmacology Biochemistry and Behavior , 100 (1), 185-190.

Yilmaz, B., Konar, V., Kutlu, S., Sandal, S., Canpolat, S., Gezen, M. R., \& Kelestimur, H. (1999). Influence of chronic morphine exposure on serum LH, FSH, testosterone levels, and body and testicular weights in the developing male rat. Archives of andrology , 43 (3), 189-196.

Yoshikawa, K., \& Hong, J. S. (1983). The enkephalin system in the rat anterior pituitary: regulation by gonadal steroid hormones and psychotropic drugs. Endocrinology , 113 (4), 1218-1227.

Yu, J., Zhang, S., Epstein, D. H., Fang, Y., Shi, J., Qin, H., .. \& Lu, L. (2007). Gender and stimulus difference in cue-induced responses in abstinent heroin users. Pharmacology Biochemistry and Behavior , 86 (3), 485-492.

Zacny, J. P., \& Beckman, N. J. (2004). The effects of a cold-water stimulus on butorphanol effects in males and females. Pharmacology Biochemistry and Behavior, 78 (4), 653-659.

Zhang, X., Zhang, Y., Asgar, J., Niu, K. Y., Lee, J., Lee, K. S., .. \& Ro, J. Y. (2014). Sex differences in $\mu$-opioid receptor expression in trigeminal ganglia under a myositis condition in rats. European journal of pain , 18 (2), 151-161. 